\title{
ARQUITECTURA PREHISPÁNICA LIMEÑA DE LOS SIGLOS XI AL XV: EL CASO DE LA CONSERVACIÓN DE LA PIRÁMIDE A DE MATEO SALADO ${ }^{* *}$
}

\author{
PREHISPANICAL ARCHITECTURE OF LIMA BETWEEN XI AND XV CENTURIES: \\ THE CASE OF THE CONSERVATION OF MATEO SALADO'S A PYRAMID \\ MIRNA SOTO MEDINA ${ }^{(* x)}$ Y JULIO VARGAS NEUMANN ${ }^{[(*+\infty)]}$ \\ Fecha de recepción: 15 de abril de 2015 \\ Fecha de aprobación: 11 de mayo de 2015
}

\section{RESUMEN}

Desde el año 1000 de la era cristiana hasta finales del período prehispánico, floreció en Lima la cultura Yschma. De ella han quedado numerosas huacas o edificaciones prehispánicas, que se caracterizan por tener a la tierra como principal material de construcción, desde mortero para asentar piedras hasta grandes bloques de tierra y enlucidos. Son testimonio histórico de este período sitios arqueológicos como el Complejo Maranga, ubicado en el actual Parque de las Leyendas, la Universidad Católica y la Universidad San Marcos, y otros como Mateo Salado, Huaca La Luz, Huantille, Huantinamarca, San Borja, La Merced y muchos más. Estas edificaciones han sido seriamente afectadas por el paso del tiempo, los movimientos sísmicos y el avance de la modernidad. En este ensayo se presenta la descripción constructiva-estructural del Complejo arqueológico Mateo Salado (1100 d.C. - 1532 d.C.), y los trabajos de conservación y consolidación realizados en el año 2007 en la pirámide A por un equipo interdisciplinar que integró arqueología, conservación e ingeniería estructural, que se rigió por los conceptos de respeto a la autenticidad, conocimiento profundo de la fábrica, seguridad estructural e intervención de mínimo impacto en el valor cultural.

\section{PALABRAS CLAVE}

Huaca, Ychsma, tierra, conservación

\section{ABSTRACT}

Since year 1000 of the Christian era to the late pre-Hispanic period, the Yschma culture flourished in Lima. Its heritage are numerous huacas or pre-Hispanic buildings, which are characterized by soil as the main building material, from mortar to lay stones to large blocks and plasters. Historical testimony of this period are archaeological sites like the Maranga Complex, located in the current Parque de las Leyendas, the Catholic University and the University of San Marcos, and others like Mateo Salado, Huaca La Luz, Huantille, Huantinamarca, San Borja, La Merced and many more. These buildings have been seriously affected by the passage of time, earthquakes and the advance of modernity. This essay presents the constructive - structural description of the archaeological complex Mateo Salado (1532 AD - $1100 \mathrm{AD}$ ), and the conservation and consolidation work performed in 2007 in the pyramid $\mathrm{A}$, developed by an interdisciplinary team that integrated archeology, conservation and structural engineering, which was oriented by the concept of respect for authenticity, deep knowledge of the constructive material, structural safety and intervention with minimal impact on the cultural value.

\section{KEYWORDS}

Huacas, Yschma, soil, conservation

${ }^{*}$ ) El presente estudio es producto de las investigaciones llevadas a cabo por el equipo de conservación que trabajó en el Complejo Arqueológico Mateo Salado en el período 2007-2009. Los resultados de estos estudios fueron presentados por primera vez como ponencia en el evento Terra 2012, que se llevó a cabo en la Pontificia Universidad Católica del Perú, pero se desarrollan con mayor profundidad en el presente artículo.

${ }^{(* *)}$ Arquitecta egresada de la Universidad Nacional de Ingeniería. Especialista en Restauración de Monumentos Arquitectónicos y Arqueológicos. Estudios de Maestría en Conservación del Patrimonio Edificado en la Universidad Nacional de Ingeniería. Especializaciones en Restauración de Monumentos, Protección de Centros Históricos y Zonas Arqueológicas en España e Italia. Profesora en la Universidad Peruana de Ciencias Aplicadas.

(***) Ingeniero, profesor principal en la Universidad Católica del Perú, investigador de Construcciones de Tierra Sismorresistentes, ex viceministro de Vivienda, Premio Nacional de Cultura en Ciencias y Tecnología 1985/86, presidente del Comité Especializado Norma NTE.E-080 Adobe, miembro de ISCEAH, ISCARSAH, ICORP/ICOMOS y Junta Directiva ICOMOS Perú. Condecoración Orden al Mérito. Ministerio de Vivienda del Perú. 


\section{Tierra, Huacas y Dios}

Antes de la conquista del Perú por los españoles, el proceso cultural histórico de la comarca limeña estuvo marcado por el desarrollo de la cultura Yschma bajo la influencia Inca.

Entonces el paisaje limeño estaba dominado por la presencia de caminos que lo vinculaban con todo el territorio andino. Una larga red de canales y acequias creadas con la finalidad de irrigar el árido suelo lograron ampliar cada vez más la frontera agrícola, y los apus ${ }^{1}$, como celosos vigías, participaban de la vida cotidiana de la sociedad andina e inspiraban la edificación de notable arquitectura.

Por su bondad y gran influencia en el desarrollo de la vida, la naturaleza fue divinizada. En la cultura andina, el paisaje es considerado sagrado, y el vínculo entre el hombre y los dioses es muy cercano; la dependencia es total. A la tierra, por su fertilidad, se le conferían rasgos femeninos, mientras que el río fertilizador fue adjudicado rasgos masculinos; de la íntima unión de ambos nace la vida. La tierra es la madre: Pachamama en quechua, que es el lenguaje inca.

En la costa peruana abunda la tierra; por lo tanto, esta es utilizada como material de construcción que, además, otorga carácter sagrado; le confiere sacralidad al edificio en sí mismo. Muros, pisos y pinturas de tierra son elementos de culto. La huaca ${ }^{2}$, término que se emplea en la costa peruana para designar las edificaciones prehispánicas, es sagrada porque sagrado es el dios que representa, la tierra que la edifica y el espacio donde se encuentra. Las huacas renacen cíclicamente y como parte de ese proceso el edificio crece a través del rito de enterramiento; al culminar una etapa de su desarrollo se inicia otra sobre la base de la anterior.

Los ychsma fueron el señorío que se desarrolló en la parte baja de los valles del río Rímac y Lurín a partir del año 1000 a.C., que en su última fase alternó con los incas, cuando estos llegan a la costa central. Cuando el padre Antonio de la Calancha recoge versiones de los nativos de la región sobre el significado de la palabra ychsma, estos hacen referencia al color rojo extraído del achiote, color que tendría un significado especial para la sociedad de esa época. Los Yschma eran tributarios del dios Pachacámac.

Entre las principales edificaciones de la cultura Yschma están las huacas ubicadas en el Complejo Maranga: en el actual Parque de Las Leyendas (San Miguel, Tres Palos, Cruz Blanca), la actual Universidad Católica (camino epimural) y la actual Universidad de San Marcos. Además, existen otras, como Mateo Salado, Huantinamarca, Huantille y más.

La arquitectura ychsma es del tipo pirámide trunca escalonada; consta de escaleras de acceso, plazas en los niveles bajo y alto de la pirámide, recintos cerrados anexos a esos espacios, pasadizos cortos y plataformas. Ceremonias que congregaban a numerosas personas debieron realizarse en las plazas públicas, mientras que los recintos altos eran espacios más restringidos. La función de estos recintos altos era predominantemente ceremonial y administrativa.

1. El término apu significa en quechua señor grande, juez superior, curaca principal o rey (González, [1608] 1989); en la religiosidad andina prehispánica representaban a las deidades tutelares personificadas en diversos elementos de la naturaleza, principalmente montañas, que controlan los fenómenos meteorológicos y la vida de las personas de las aldeas vecinas, quienes le rendían culto y propiciaban ofrendas acorde a las necesidades y exigencias del apu, por ejemplo, los fenómenos asociados a la actividad volcánica eran muy temidos y respetados. (Vitry, 2008, pp. 47-65)

2. Huaca es una voz indígena -presente tanto en el idioma quechua como aimara- cuyo significado original puede ser traducido como sagrado. Con este término se hacía alusión a lugares de culto, objetos, animales, plantas e incluso personas, tanto vivas como muertas, todos ellos calificados como sacros. (Villacorta, 2010, p. 13) 
Agrupadas, las edificaciones Yschma conforman grandes complejos, como el Maranga, que tiene 14 pirámides y 50 edificios menores, y se cree habría sido la sede de los jerarcas principales. También existen complejos medianamente grandes, como Mateo Salado, que consta de cinco pirámides y fue sede de un importante funcionario local. Además, también están las huacas aisladas, mayormente asociadas a acequias desde donde se cumplía una función administrativa de control de aguas, como las huacas La Merced, San Borja y Balconcillo, entre otras.

\section{Antecedentes}

\section{Reseña Histórica}

En los valles de Lurín y Rímac, tras el declive de la cultura lima y el fin de la influencia wari, emergieron naciones locales, entre ellas la cultura Yschma (1100 - 1450 d.C.), que tuvo como sede el santuario de Pachacámac, oráculo al que acudían los gobernantes de la comarca de Lima. Los dominios Yschma estuvieron conformados por pequeños curacazgos, tales como Lati, Sulco, Huadca y Maranga, entre otros, cada uno al mando de jefes locales.

El curacazgo de Maranga abarcó los actuales distritos de San Miguel, Pueblo Libre, Magdalena y el Cercado de Lima. La sede de gobierno fue el área que hoy ocupa el Parque de Las Leyendas. Documentos de los siglos XVI y XVII cuentan que era llamada Malanca - Maranga, ambas palabras provenientes del quechua marai (piedra de moler), en posible referencia a los amplios centros de procesamiento de alimentos existentes en ella.

Se trató de una urbe prehispánica con grandes palacios y templos de tapial. Los palacios de los curacas Ychsma habrían sido las pirámides con rampa, como las de Pachacamac, Maranga (Huaca La Palma), etc. El complejo Maranga, por ejemplo, fue grande y colorido; estaba compuesto por templos, palacios y centros administrativos de forma piramidal que poseían murales pintados con ocre-amarillo, en los cuales se representaba personas, animales, y dibujos geométricos en alto y bajo relieve. La organización de este complejo se complementó con elementos como plazas, caminos y pasajes epimurales. En el campo, entre las áreas de cultivo, se ubicaban viviendas de quincha.

El último curaca de Maranga, Chayavilca, vivió hasta 1542. Tras su muerte, sus tierras fueron entregadas a Nicolás de Rivera el Mozo, nuevo gobernante español.

Los patrones urbano-arquitectónicos y los sistemas constructivos del complejo Maranga corresponden a los que se observan en el Complejo Mateo Salado, pues pertenecen a la misma cultura y época, además de su proximidad geográfica. Asociar los patrones culturales de ambos complejos, debido a que el mismo grupo humano los planeó, edificó y utilizó, es de crucial importancia para profundizar su comprensión.

\section{Eventos Históricos en el Complejo Mateo Salado}

El complejo arqueológico Mateo Salado constituye uno de los complejos urbanísticos más extensos e importantes de época tardía en la costa central precolombina. Perteneciente a la cultura Yschma, está asociado cronológica y geográficamente al complejo urbano de Maranga, lo cual permite deducir que se trataría de un complejo administrativo-ceremonial perteneciente a un funcionario de élite. Sin embargo, no se han encontrado referencias históricas sobre su función, aunque ha sido "designada por viajeros tan respetables como Hutchinson, como la Waka o Templo del Dios Rímac. (...) Todo hace pensar que este sea el Templo del Rímac, porque no se halla en la vieja documentación de la Conquista y de la Colonia, referencia alguna sobre el nombre indígena de este sitio." (Tello, 1999, p. 102). Adicionalmente, el complejo arqueológico también figura como "huaca Ascona", debido a que se encuentra dentro de los terrenos de la antigua hacienda del mismo nombre. También se le conoce como Huaca Cinco Cerritos por la cantidad de pirámides que alberga. 


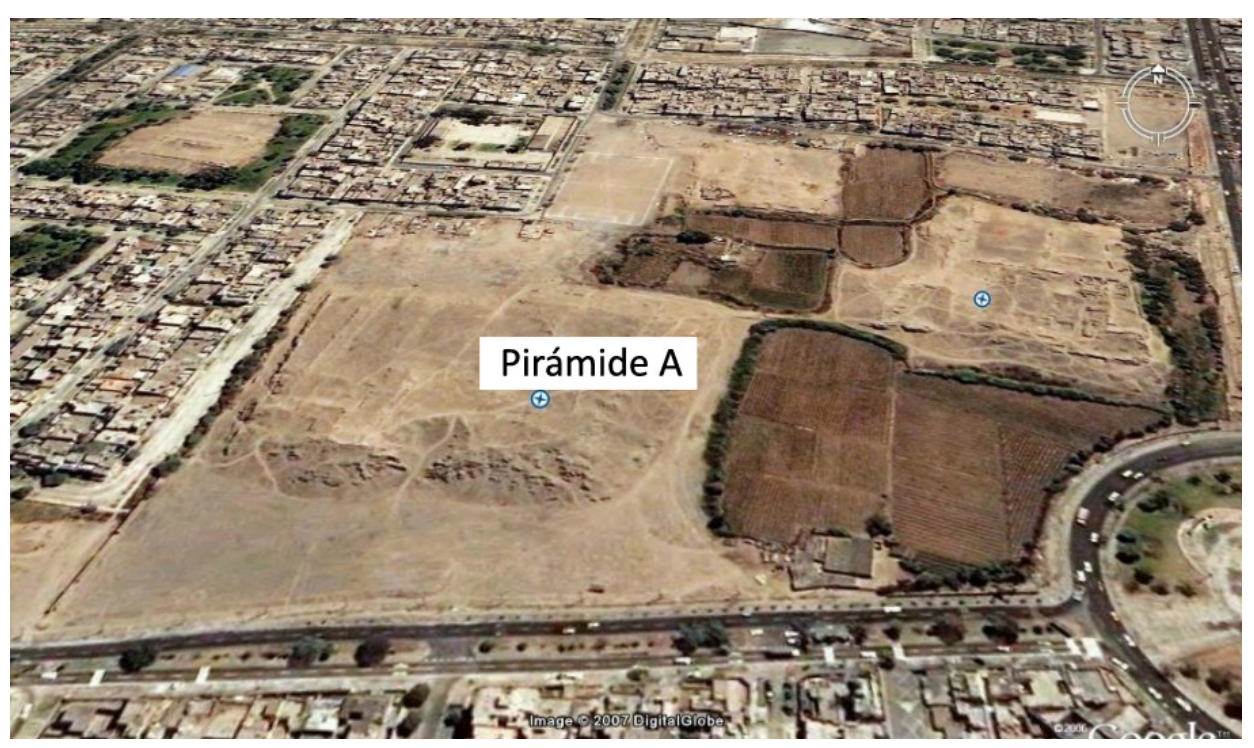

La zona arqueológica debe su nombre al inmigrante francés Mateo Salade (15281573), quien llegó al Perú, presumiblemente por el puerto del Callao, a mediados del siglo XVI, escapando de la persecución religiosa en Francia. Mateo Salade vivió en la zona arqueológica que hoy lleva su nombre como un ermitaño, debido a la persecución de la que fue víctima a causa de su fe luterana. Fue acusado de blasfemo, hereje contumaz y de decir palabras impías. Además, se le consideró "falto de juicio", puesto que se le veía distraído, trabajando solo y aparentemente en vano en la huaca. Finalmente fue apresado en 1571 por la Santa Inquisición y ejecutado en la hoguera el 15 de noviembre de 1573 en el primer Auto de Fe realizado en la Plaza Mayor de Lima.

En los años 30, Julio C. Tello visitó el Complejo Mateo Salado e hizo algunas anotaciones sobre su arquitectura, que luego fueron publicadas por el Museo de Arqueología de la Universidad Nacional Mayor de San Marcos. Ya en esa época, Tello registró los daños causados al monumento por el paso del tiempo y la ocupación humana, ya que se había instalado allí una ladrillera.

El complejo ha sufrido numerosas depredaciones: las más graves ocurrieron en 1940, cuando la Compañía Urbanizadora AVEP, inconsultamente, inició la demolición del monumento, y en 1963, como consecuencia de la formación de una barriada inmediata a las ruinas, en la intersección de las avenidas Tingo María y 28 de Julio (hoy Mariano Cornejo). La invasión de Mateo Salado ocasionó el desalojo temporal de los invasores. Posteriormente a la culminación de dicho desalojo temporal, la destrucción del monumento se aceleró. En sus inmediaciones se estableció un mercado, y parte del terreno fue invadido por diversos agricultores y ocupado por trabajadores precarios. En 1979, durante la construcción del Parque de La Bandera, la Municipalidad de Pueblo Libre demolió el único paño conservado de la antigua muralla perimetral (Ravines, 1985).

En la década de los años 80, en coordinación con los vecinos, el Instituto Nacional de Cultura (INC) construyó un muro perimétrico de pilotes de concreto y malla de alambre alrededor del Sector A, que actualmente sobrevive parcialmente, y colocó pequeños letreros de señalización en los límites de la zona arqueológica (Sectores A y B). En el año 2000, la licenciada Maritza Pérez Ponce, del Museo de Arqueología, Antropología e Historia del Perú (MNAAHP), llevó a cabo un proyecto de investigación y conservación en la pirámide B del complejo, que incluyó tareas de proyección social e integración con el MNAAHP; los resultados de los trabajos se encuentran publicados en los Cuadernos de Investigación del Museo (Pérez, 2004).
Figura 1. Vista aérea del Complejo arqueológico Mateo Salado, señalando la ubicación de la Pirámide A. Fuente. www.google.com/earth, 2015. 


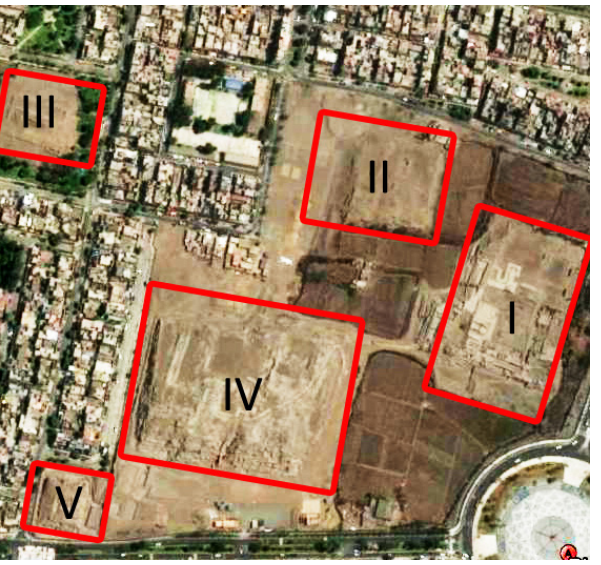

Figura 2. Vista aérea del Complejo Arqueológico Mateo Salado, señalando la ubicación de las cinco pirámides según denominación de Julio c. Tello.

Fuente. Elaboración propia, Mirna Soto, 2015.
En el año 2007 asumió la dirección del proyecto la licenciada Alejandra Figueroa, quien lideró la intervención que se llevó a cabo en la Pirámide A del complejo (Figura 1). Los trabajos fueron ejecutados por un equipo interdisciplinar de conservación arquitectónica, ingeniería estructural y arqueología. Se aplicaron, por primera vez, los resultados de las investigaciones teórico-experimentales realizadas en la Pontificia Universidad Católica del Perú, en las cuales se desarrollaron técnicas de inyección de suelo arcilloso líquido para reparar fisuras en muros de adobe. Ello fue posible gracias al convenio de colaboración público-privado entre el INC (hoy Ministerio de Cultura) y dicha universidad. Desde entonces la investigación arqueológica, la conservación y la puesta en uso del monumento han continuado bajo la dirección del arqueólogo. Pedro Espinoza, proceso en que se ha implementado la iluminación nocturna y la apertura al público.

\section{Aspectos Arquitectónicos}

El complejo arqueológico está constituido por cinco pirámides monumentales, cuatro de las cuales se ubican dentro del Sector A (pirámides A, B. C y E). Originalmente, el complejo se hallaba conectado mediante un estrecho camino amurallado con el Complejo arqueológico Maranga, ubicado dentro del terreno actual del Parque de las Leyendas.

La Pirámide A es la más grande de las que se encuentran en el sector A; se ubica sobre una gran explanada rectangular de 164 por 132 metros, tiene más de 15 metros de altura y, aparentemente, está compuesta por grandes plataformas superpuestas. Esta pirámide es altamente visible desde los alrededores, tanto para los vecinos como para los transeúntes, ya que su lado sur está sobre la avenida Mariano Cornejo, por la que continuamente transitan vehículos.

IV. Entre las wakas anteriores y hacia el lado S aparece la waka mayor, de forma más o menos rectangular. Se halla unida por una especie de puente o muro con la I, muro o puente que hoy sirve de acequia. Con las otras dos huacas no tiene conexión, salvo que los muros hayan desaparecido. Es la más importante del grupo de los Cinco Cerritos. Tiene muros de circunvalación con callejones o pasajes que, probablemente, dan acceso a las plataformas superiores. Los muros son de adobones, gruesos, altos, y hay señales de acrecimiento. En la parte superior existen grandes patios o canchones que tienen comunicaciones con terrazas o habitaciones por medio de graderías o muros inclinados. La altura de esta waka es de más de 20 m... [...]

Muro de circunvalación.- El grupo de wakas de halla protegido por medio de un elevado muro de adobón. Por el lado $\mathrm{N}$ aparece a unos $200 \mathrm{~m}$. de las wakas I y Il; por el lado S también pasa a unos 50 ó $100 \mathrm{~m}$. de las I y IV, y al pie de la V, por el E, pasa a unos 10 ó $20 \mathrm{~m}$. de la l; y por el lado O no existe resto alguno (Tello, 1999, p. 33) (Figura 2).

En aquel año de 1935, yo identifiqué, sirviéndome de parte de la descripción de Middendorf, la mayoría de los edificios principales que se levantaban sobre la plataforma superior, las terrazas, viviendas y cámaras de los contornos, los muros que encierran el montículo y, por último, la entrada que tiene por el lado N. Todavía quedan restos de esta entrada, pero ya no existen las puertas del lado $\mathrm{N}$ que eran las principales; el terraplén o especie de mirador del borde $\mathrm{N}$ de la plaza o patio principal de la plataforma superior; los asientos socavados en los gruesos muros que limitan la plataforma, y las viviendas, de los lados E y S, y el cementerio del lado Oeste. Todas las estructuras existentes en aquel año están registradas en el plano adjunto. (Tello, 1999, p. 103)

\section{La Técnica de Construcción Yschma}

\section{Materiales Empleados por los Yschma. Propiedades Mecánicas}

El hombre siempre ha dispuesto de los materiales accesibles en su territorio, los cuales ha articulado y combinado para formar sistemas constructivos que, a lo largo de la historia, se han vuelto cada vez más complejos y eficientes. El suelo limeño es mayormente un suelo aluvial, producto de la acumulación de sedimentos acarreados por avalanchas de lodo y piedra; por lo tanto, los principales materiales de los que disponían los Yschma eran tierra y piedra. 
devenir Vol. 2, N³, ENERO- JUNIO 2015, PP. 22-44 - ESTUDIOS I ISSN 2312-7570

UNIVERSIDAD NACIONAL DE INGENIERÍA, LIMA

Gráfico 1. Adherencia y resistencia. Fuente. Elaboración propia, Mirna Soto, 2015

Figura 4. Bloques de Tierra Modelada: Macizos.

Fuente. Archivo fotográfico Mirna Soto, 2015.

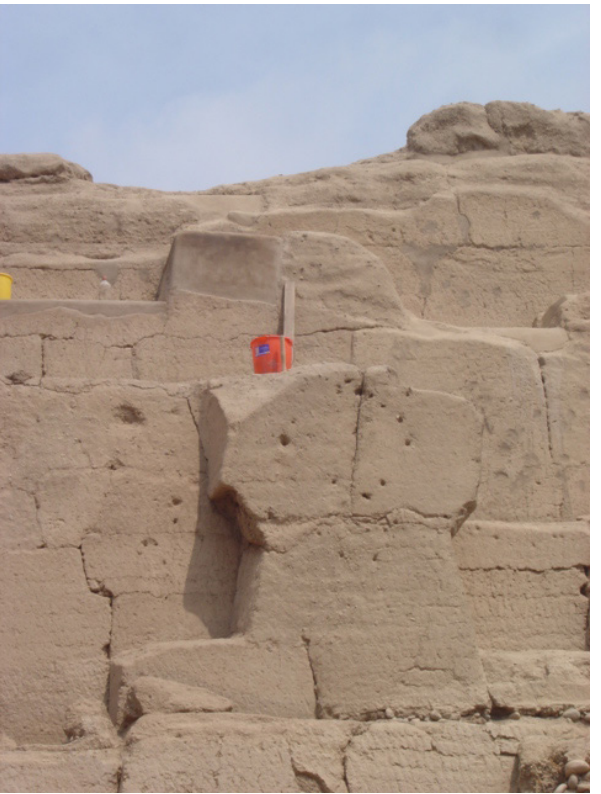

\section{-Muro de baja resistencia}

\section{-Componentes de superficie lisa y redondeada, provoca desmoronamiento.}

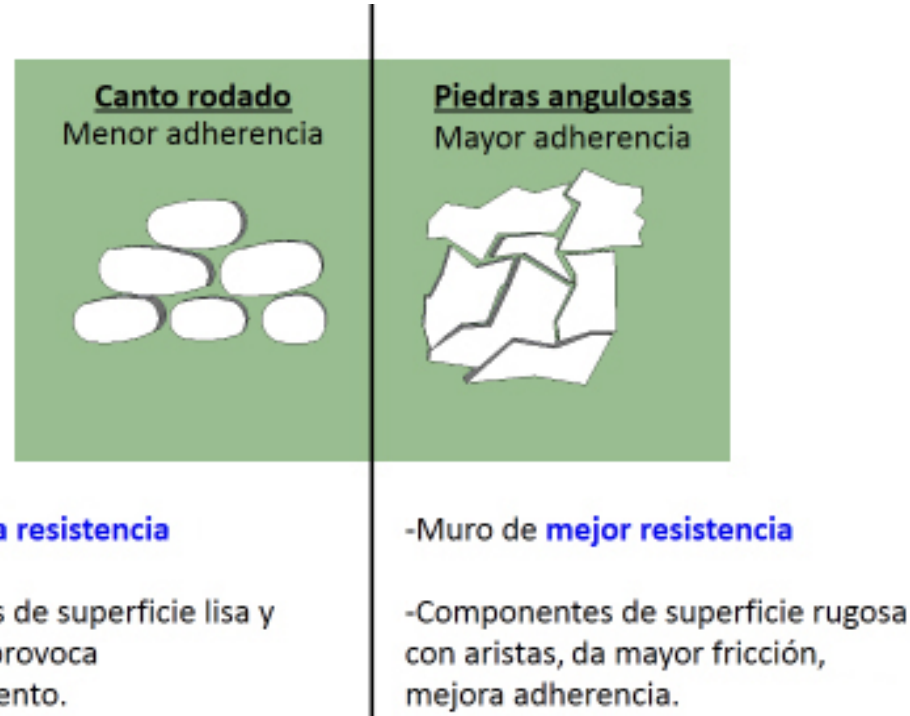

La tierra y la piedra son los dos materiales de construcción más accesibles de la naturaleza, pero son poco compatibles. Los morteros de tierra facilitan el asentado de la piedra para construir un muro, pero un muro de piedra asentado con morteros de tierra resiste mucho menos que un muro de tierra cruda, ya sea de albañilería de adobe o de tapial. La adhesión entre los dos materiales es muy débil, y el peso específico de la piedra es alrededor de 50\% mayor que el de la tierra cruda seca; por tanto, si los morteros mantienen unidas piedras más pesadas que los adobes, son más vulnerables. Tal es el caso de las pirkas, ampliamente utilizadas en el Perú desde épocas ancestrales (Gráfico 1).

\section{Componentes Constructivos}

El sistema constructivo apreciado en las pirámides Yschma está conformado principalmente por muros y rellenos estructurales. Estos elementos están compuestos por dos tipos de bloques: bloques macizos y bloques rellenos.

\section{Bloques macizos: BTM macizos}

El tapial consiste en una gran unidad de mampostería fabricada in situ, mediante la utilización de algún tipo de encofrado o elemento de contención de la masa de barro en estado plástico, que es depositada en su interior por capas que se compactan entre sí. El grado de compactación es una variable cultural que está asociada a la resistencia. Esta técnica permite elaborar elementos estructurales de gran masa que, adecuadamente conectados, pueden otorgar mayor estabilidad. Ello supone un proceso de cuidadosa elaboración, en el cual es crucial proporcionar el adecuado porcentaje de humedad a la tierra, que debe ser menor que el del adobe, y requiere mayor cantidad de arena gruesa para controlar la contracción brusca y la posible adición de partículas mayores a la arena gruesa, dado el volumen del material.

Los grandes bloques de tierra elaborados por los Yschma, en tanto elementos estructurales, representan un aporte significativo aprovechable para el mejoramiento de las técnicas de construcción. Al tratarse de un elemento continuo de tierra maciza medianamente apisonada, que conforma bloques de grandes dimensiones, se consigue la disminución de la cantidad de juntas de mortero de barro, que por lo general son las partes más débiles de un muro. Esta disminución del número necesario de juntas asegura mayor homogeneidad y monolitismo. Por lo tanto, esta mampostería es menos vulnerable que el adobe (Gráfico 2). 


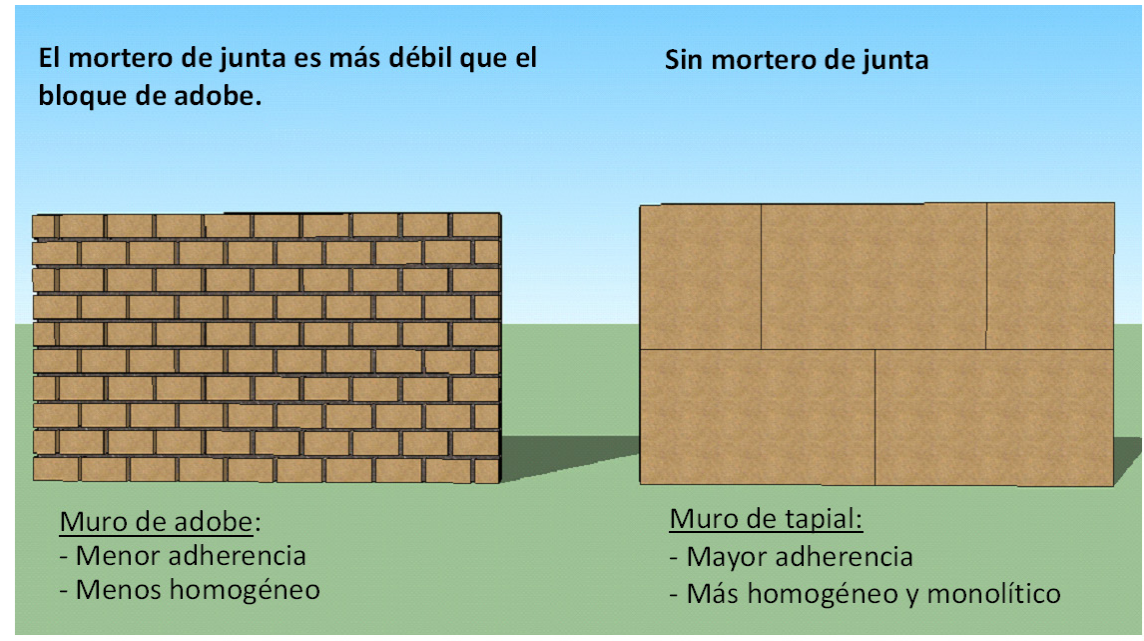

Por tanto:

La mampostería de tapial es menos vulnerable que la de adobe.
Gráfico 2. Muro de adobe vs. Muro de tapial.

Fuente. Elaboración propia, Mirna Soto, 2015.

La técnica de elaboración Yschma de bloques macizos es aún desconocida. No hay evidencias del empleo de encofrados rígidos que permitieran una compactación importante; sin embargo, una fina textura sobre la superficie de los tapiales en Mateo Salado hace suponer el empleo de esteras, lo cual podría haber contribuido a controlar la inclinación exterior de los bloques. Al colocar la masa de barro de manera horizontal por capas o tongadas, estas debieron ser emparejadas con las manos, lo que les hubiese dado mediano grado de compactación.

Por lo tanto, puede inferirse que el sistema constructivo empleado por los Yschma no fue precisamente el tapial, dado que no existe evidencia del uso de encofrados rígidos: probablemente, la tierra fue sido colocada in situ y modelada a mano. Se trataría pues, de Bloques de Tierra Modelada o BTM³ .

La fabricación de estos bloques respondió a dos factores: en primer lugar, al relativo grado de compactación del barro y, en segundo lugar, al total despliegue de las propiedades de la arcilla, que solo se consigue mediante una adecuada selección y preparación del barro (este debió ser "vertido" en estado plástico, es decir, con poca humedad, lo cual impide que se raje y desintegre). Esto se comprobó a partir de la observación de bloques rotos; en ellos la separación se había producido precisamente en el área de contacto entre dos capas o tongadas de tierra, casos en los que la superficie intermedia es ligeramente más lisa que el resto.

La geometría irregular de los bloques revela el empleo de encofrados no convencionales, cuyas formas respondieron definitivamente a los fines constructivos y estructurales de los Yschma, debido a que permite colocar un bloque encima del otro de manera que, al secarse, la gravedad contribuya a mantenerlos unidos; la superficie lateral del bloque elaborado previamente recibe y sirve de apoyo al bloque nuevo. Asimismo, la irregularidad de los bloques, sus varias formas y ángulos, aumenta la superficie de contacto; por lo tanto, hay más rozamiento y mayor trabazón. De esta manera las juntas constructivas contribuyen a aumentar el monolitismo del muro y controlar los desplazamientos laterales. 


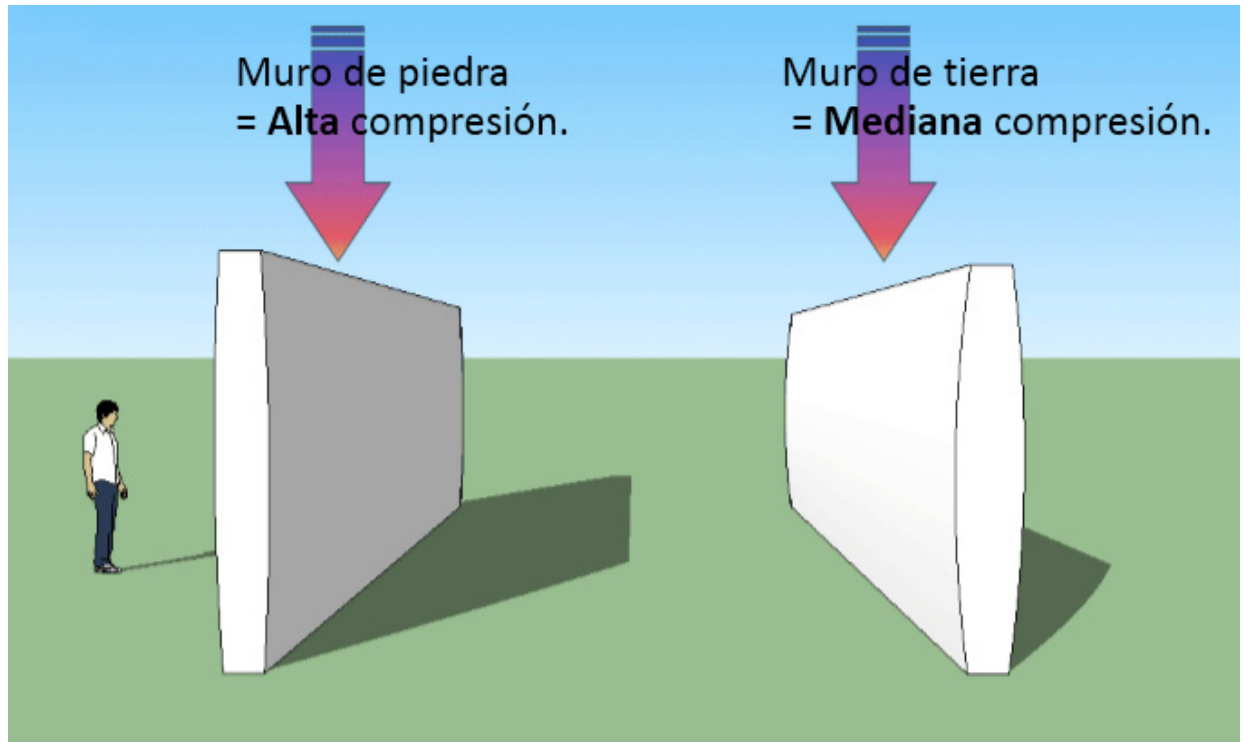

Ya que la piedra es entre 15 y 20 veces más resistente a la compresión que la tierra seca, se utilizó esta técnica de parrillas con la finalidad de aminorar el peso de las cargas superiores. Sin embargo, al ser un sistema no consolidado (tierra y piedras sueltas), este debe haber generado empujes laterales no controlados, por lo que la resistencia frente a sismos habría sido deficiente (Gráfico 4).

En el caso del camino preinca, se aplicó el mismo concepto: está compuesto de un núcleo de tierra y piedras que favorece la disminución de esbeltez y, por tanto, aumenta la estabilidad ante el riesgo de volteo, pero a la vez genera empujes laterales desfavorables en caso de sismo. La pérdida de los bloques que confinaban el relleno durante los sismos ocasionó el colapso de los emparrillados y la pérdida de la estabilidad estructural de la pirámide (Figura 6).

\section{Los Sistemas Constructivos Ychsma. El Mejoramiento de las Técnicas en Base a la Experimentación}

La evolución y constante mejoramiento de los sistemas constructivos prehispánicos derivó durante el Horizonte Medio y en el período Intermedio Tardío en la técnica del BTM, que se basa, en el caso de Mateo Salado y del Camino Prehispánico Maranga, principalmente en los siguientes principios:

\section{Sistema portante}

Cada elemento de mampostería cumple la función de transmitir las cargas de su propio peso, de los techos, de los niveles altos y de las cargas vivas. Su funcionalidad depende de su resistencia a la compresión, dimensionamiento, estabilidad, equilibrio e integridad (Gráfico 5).

\section{Criterio de masa global}

Las estructuras de tierra deben su estabilidad estructural principalmente a su relación entre altura y espesor (esbeltez). Una adecuada esbeltez permite garantizar la estabilidad, especialmente cuando ocurren sismos o actúan fuerzas de inercia horizontales. En las construcciones yschma, los muros de BTM suelen tener forma trapezoidal, de tal manera que existe menor peso en la parte superior, lo cual permite que baje el centro de gravedad y los muros resistan mejor al volteo (Gráfico 6 y 7 ).
Gráfico 4. Muro de piedra vs. Muro de tierra.

Fuente. Elaboración propia, Mirna Soto, 2015.

Figura 6. Relleno: Emparrillado de cantos rodados.

Fuente. Archivo fotográfico Mirna Soto, 2015.

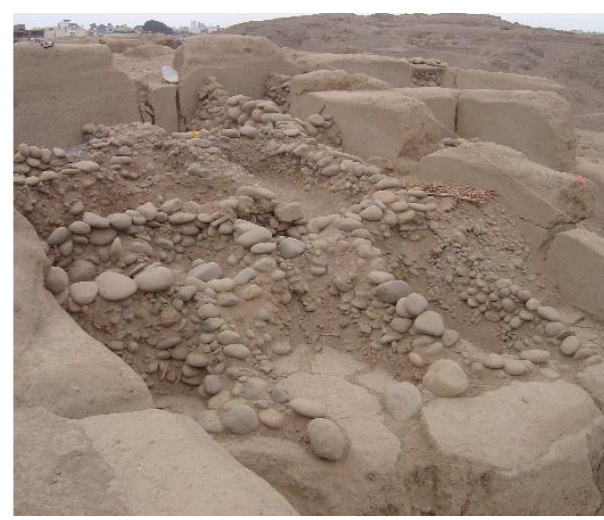


devenir Vol. 2, N³, ENERO- JUNIO 2015, Pp. 22-44 - EstudIOS I ISSN 2312-7570

UniverSIDAd NACIONAL DE INGENIERÍA, LIMA

Gráfico 5. Sistema portante de muros de tierra y piedras.

Fuente. Elaboración propia, Mirna Soto, 2015.

Gráfico 6. Estabilidad de muros y el criterio de masa global o esbeltez.

Fuente. Elaboración propia, Mirna Soto, 2015

Gráfico 7. Estabilidad en muros de sección trapezoidal.

Fuente. Elaboración propia, Mirna Soto, 2015

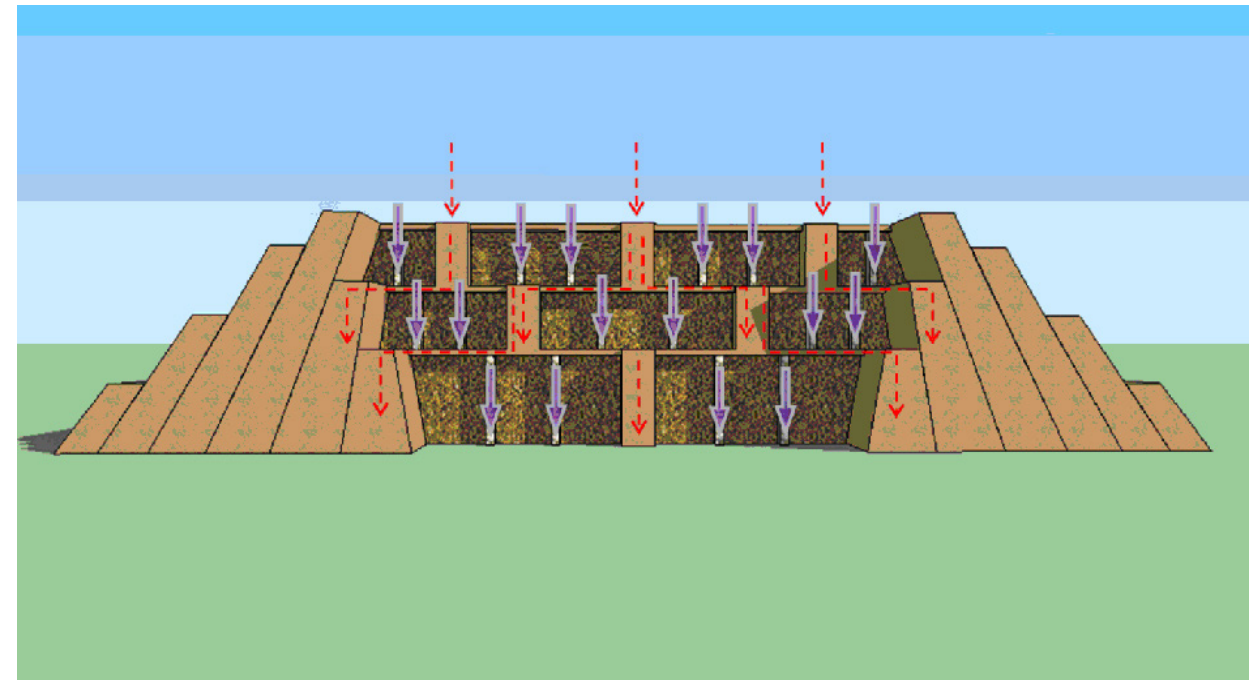

- Esbeltez = Altura $(\mathrm{h}) /$ Grosor $(\mathrm{e})$
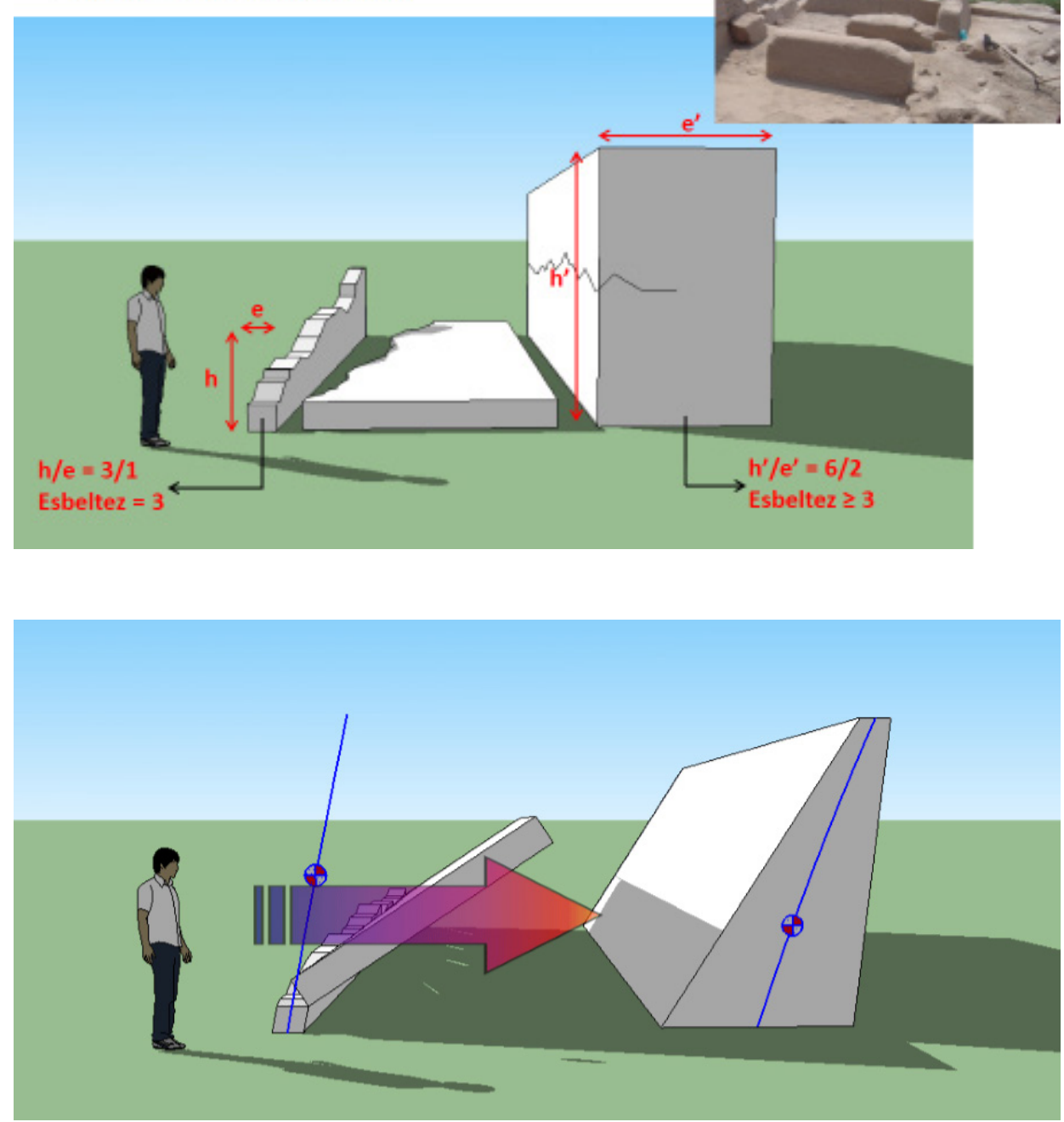

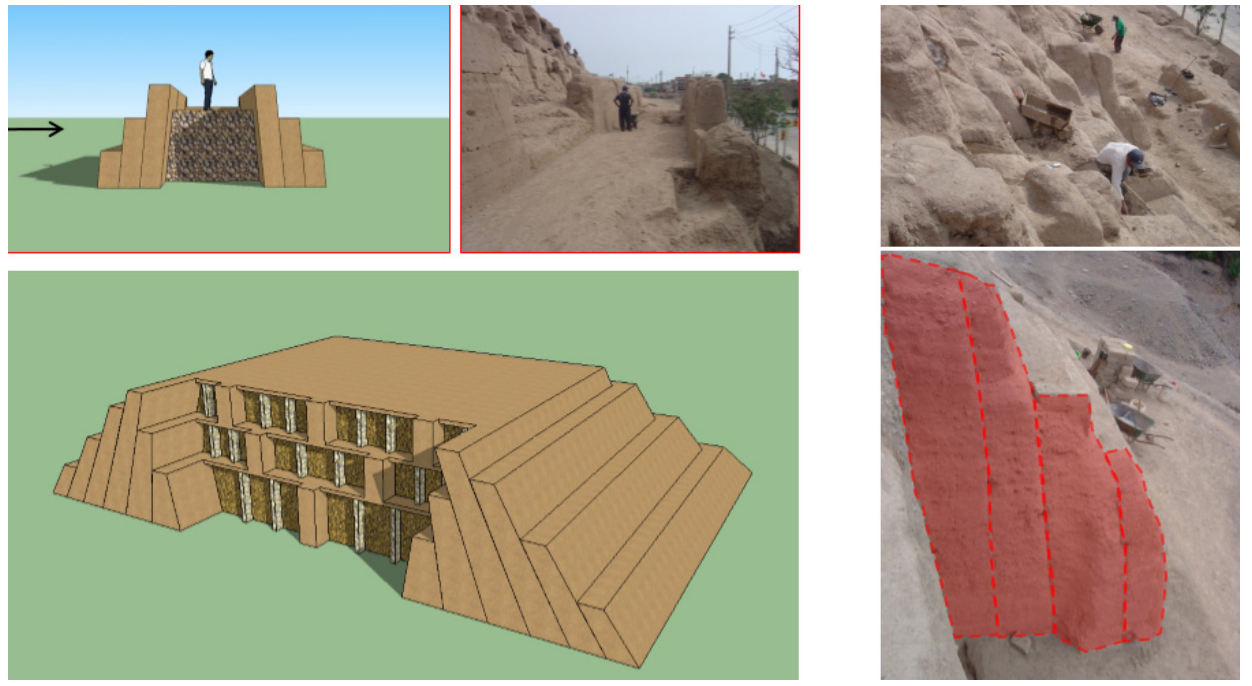

Gráfico 8. Muros adosados, sistema denominado "cáscara de cebolla" por Julio C. Tello.

Fuente. Elaboración propia, Mirna Soto, 2015.

\section{Reforzamiento de muros por medio de adosamiento de bloques inclinados formados por capas}

Cada etapa de crecimiento vertical de las pirámides de Mateo Salado debió suponer un aumento de ancho y largo del edificio, lo cual se logró adicionando nuevos bloques en las fachadas, que conforman lo que Julio C. Tello (AÑO) denominó cáscaras de cebolla. El sistema estructural del Complejo Mateo Salado apela a la resistencia de los muros exteriores, es decir, al funcionamiento de las fachadas como muros de contención de núcleo poco estable. Estas se fueron engrosando gradualmente, con una inclinación hacia adentro de aproximadamente $11^{\circ}$ (Gráfico 8).

\section{Presencia de BTM rellenos en la parte baja y externa de las fachadas}

Estos tendrían por finalidad evitar el desplazamiento de las tapias macizas externas, actuando como contrafuertes. Los rellenos al interior de las pirámides fueron realizados mediante el emparrillado de muros de cantos rodados (Figura 7).

\section{Deterioro en las Pirámides Yschma}

\section{Principales Problemas Estructurales}

Los principales problemas estructurales del Complejo Mateo Salado y de los muros del camino que unía las edificaciones de importancia son la debilidad y fragilidad del material, y la acumulación de deterioros que han afectado su estabilidad durante los terremotos. Estos dilemas se manifiestan en los siguientes casos:

\section{Falla de muros en esquina}

Los muros transversales o perpendiculares entre sí se desconectan, lo cual forma fisuras verticales, debido a que durante los sismos estos tienden a voltearse en planos diferentes. Ante la incompatibilidad de desplazamientos, se agrietan verticalmente en la unión y, ya desconectados, vibran golpeándose entre sí, lo que acelera su colapso por volteo. La magnitud de estos daños se puede apreciar en las distintas estructuras de la pirámide B (Gráfico 9).

\section{Caída de muros por volteo}

Se produce por el incremento de los empujes de los rellenos durante los sismos. La erosión basal ocasionada por acción del viento o problemas de humedad por capilaridad pueden empeorar este tipo de falla. Las fuerzas horizontales ocasionadas por
Figura 7: Colocación del relleno por capas, con parrillas de canto rodado y tierra inter-espacios de la parrilla. Fuente. Archivo fotográfico Mirna Soto, 2015.
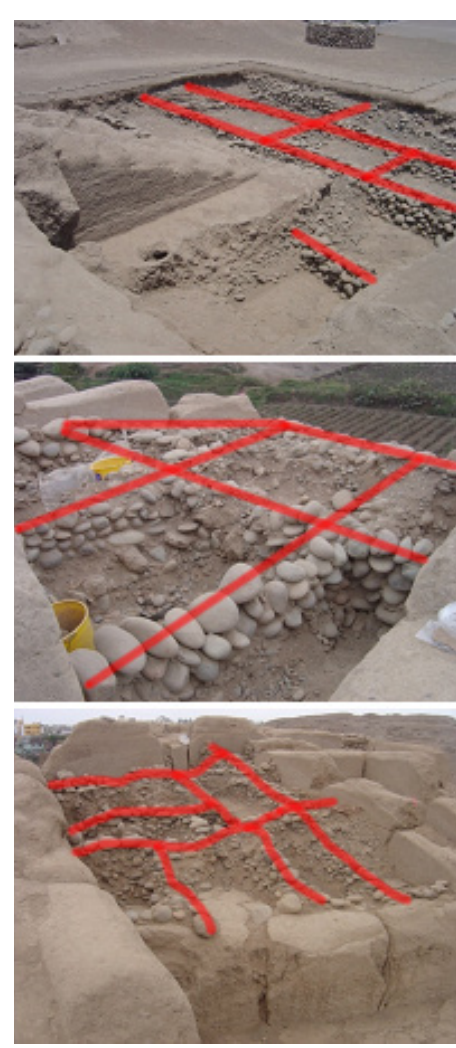
devenir Vol. 2, N³, ENERO- JUNIO 2015, PP. 22-44 - ESTUDIOS I ISSN 2312-7570

UniverSIDAd NACIONAL DE INGENIERÍA, LIMA

\section{Fallas de muros en esquinas}

Gráfico 9. Estabilidad de muros: falla por tracción.

Fuente. Elaboración propia, Mirna Soto, 2015.

Gráfico 10. Estabilidad de muros. Falla por flexión y volteo: Caso del muro libre o sin arriostre.

Fuente. Elaboración propia, Mirna Soto, 2015.

Gráfico 11. Estabilidad de muros. Falla por flexión y volteo: caso del muro con un arriostre o lado restringido.

Fuente. Elaboración propia, Mirna Soto, 2015.
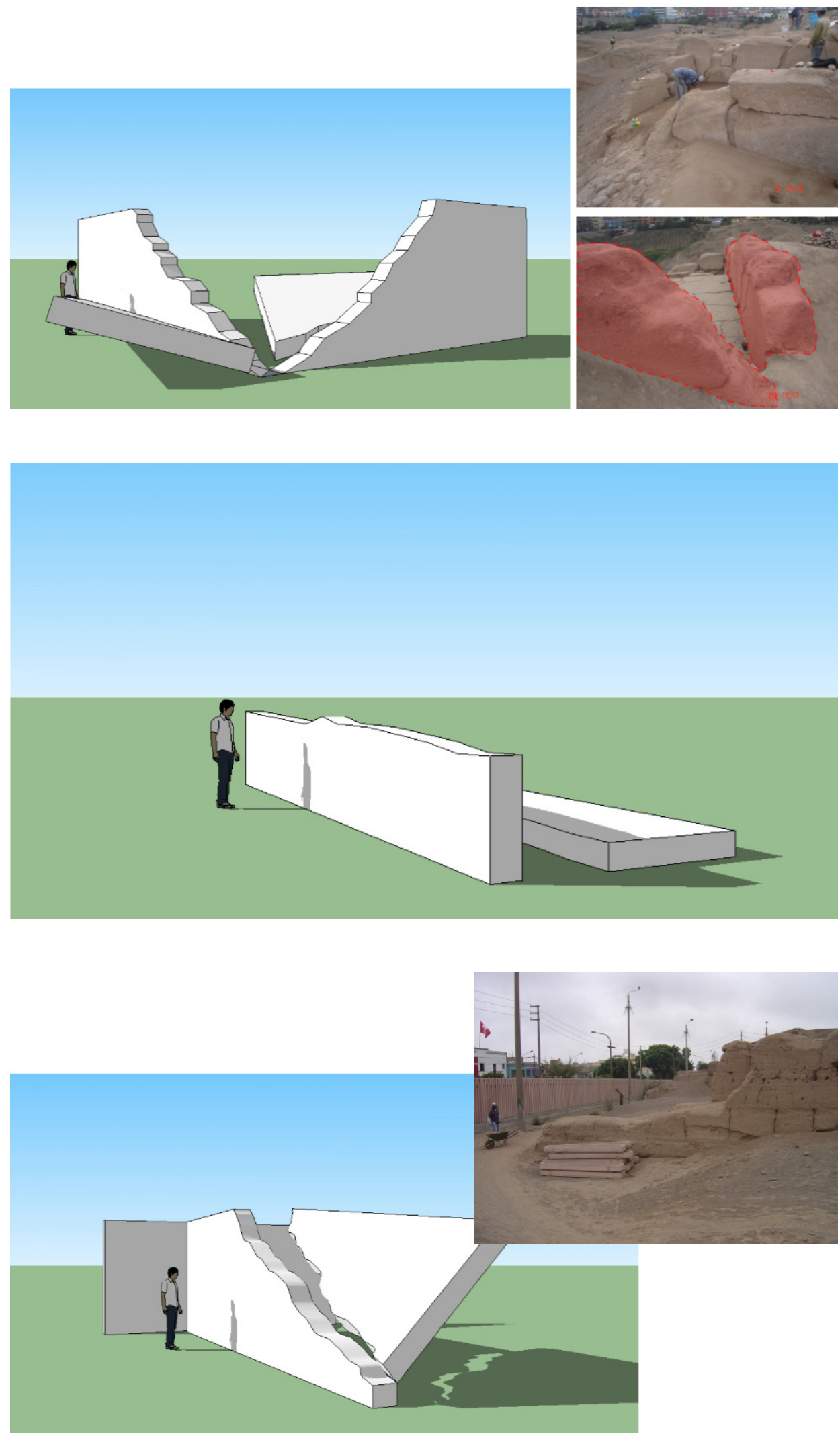


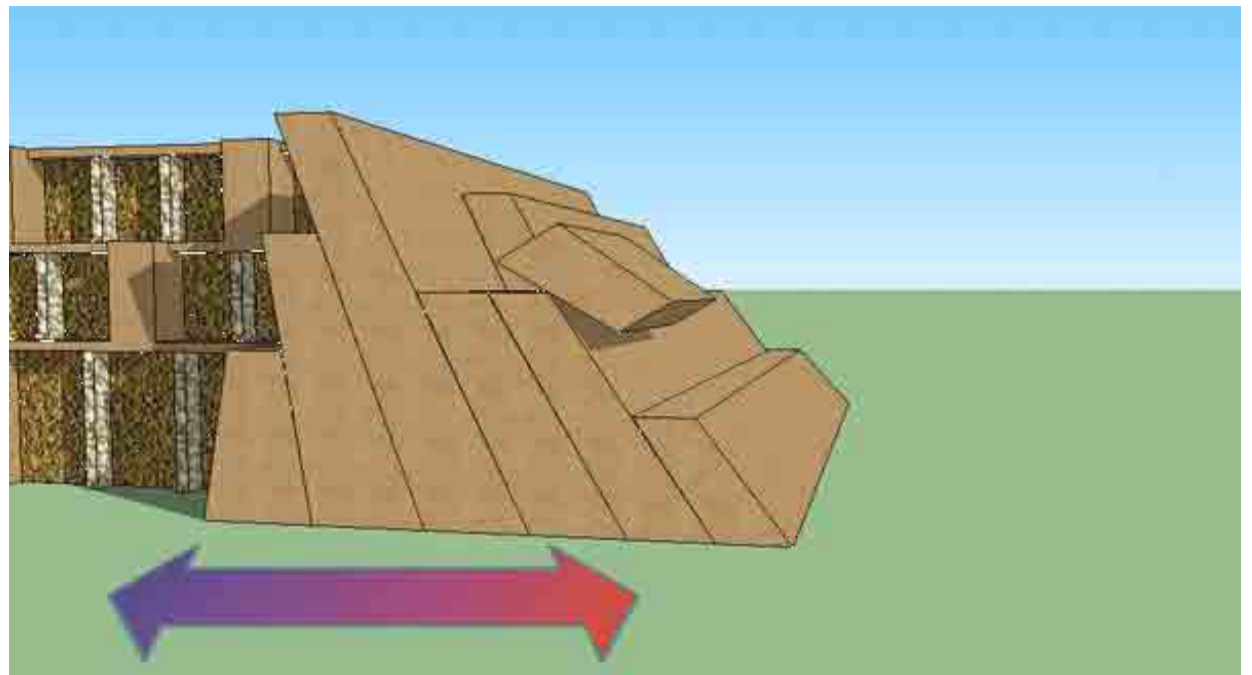

sismos suelen afectar las partes más débiles de una edificación, que en este caso son las juntas entre tapia y tapia, ocasionando su desarticulación. Ello ha causado la pérdida de la parte superior de muros y, en otros casos, una apariencia escalonada en los extremos libres de los muros que quedan en pie (Gráfico 10 y 11).

\section{Desprendimiento y colapso de las capas de cebolla}

La pérdida de verticalidad de las tapias se debe principalmente a la inestabilidad frente a las fuerzas horizontales, sean estas de empuje de rellenos o generadas por movimientos sísmicos. Cuando las capas de tapias se secan, trabajan separadas; eso significa que pierden su monolitismo, lo cual disminuye significativamente su resistencia al volteo. Por ello, es frecuente ver cáscaras de cebolla deslizadas o volteadas (Gráfico 12).

\section{Falla en cabeceras por pérdida de bloques superiores}

Al producirse el deslizamiento lateral de tapias durante los sismos, resulta afectada la zona más débil del muro, el encuentro horizontal entre paños, y el bloque superior, al deslizarse hacia delante, rompe la arista externa del bloque inferior, con cortes a $45^{\circ}$ (Gráfico 13).

\section{Colapsos parciales $y$ totales}

El daño sísmico es acumulativo; es decir, los daños producidos por un sismo se sumarán a los que ocasionen los siguientes, lo cual agrava las consecuencias y provoca, paulatinamente, el colapso total. El colapso parcial observado en el frontis norte de la pirámide B produjo la pérdida de significativos sectores de muros, pisos y rellenos; la inestabilidad de dicho sector constituía un riesgo para todo el edificio (Gráficos 14, 15 y 16).

\section{Rellenos expuestos y vaciamientos}

Al fallar los bloques o muros de contención, por deslizamiento o volteo, especialmente durante los sismos, se desmoronan los emparrillados y vacían los materiales sueltos de relleno. En tales circunstancias, los BTM rellenos, también tienden a fallar debido al empuje lateral de su relleno (Figura 8).

\section{Asentamientos de pisos o plataformas}

Algunos pisos se presentan desnivelados, con rajaduras y/o desprendimientos; estas fallas son ocasionadas por el asentamiento del material de relleno sobre el cual están apoyados. El relleno de la Pirámide B del Complejo Mateo Salado es una masa relativamente suelta, la cual se compacta con cada movimiento sísmico (Gráfico 17).
Gráfico 12. Desprendimiento y colapso de las llamadas cáscaras de cebolla.

Fuente. Elaboración propia, Mirna Soto, 2015.

Figura 8. Vaciamientos de BTM rellenos.

Fuente. Archivo fotográfico Mirna Soto, 2015.

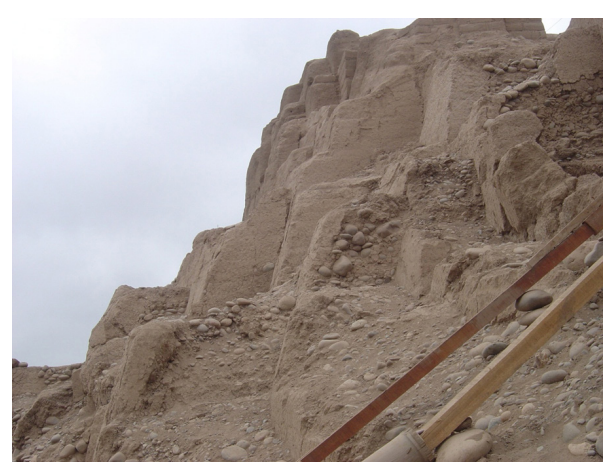


devenir Vol. 2, N³, ENERO- JUNIO 2015, Pp. 22-44 - EstudIOS I ISSN 2312-7570

UniverSIDAd NACIONAL DE INGENIERÍA, LIMA

Gráfico 13. Rotura en cabecera de bloques.

Fuente. Elaboración propia, Mirna Soto, 2015.

Gráfico 14. Deslizamiento de rellenos por desplazamiento de muro de contención.

Fuente. Elaboración propia, Mirna Soto, 2015.

Gráfico 15. Deslizamiento de rellenos por pérdida de muro de contención.

Fuente. Elaboración propia, Mirna Soto, 2015.
- Falla en cabeceras por pérdida de bloques superiores
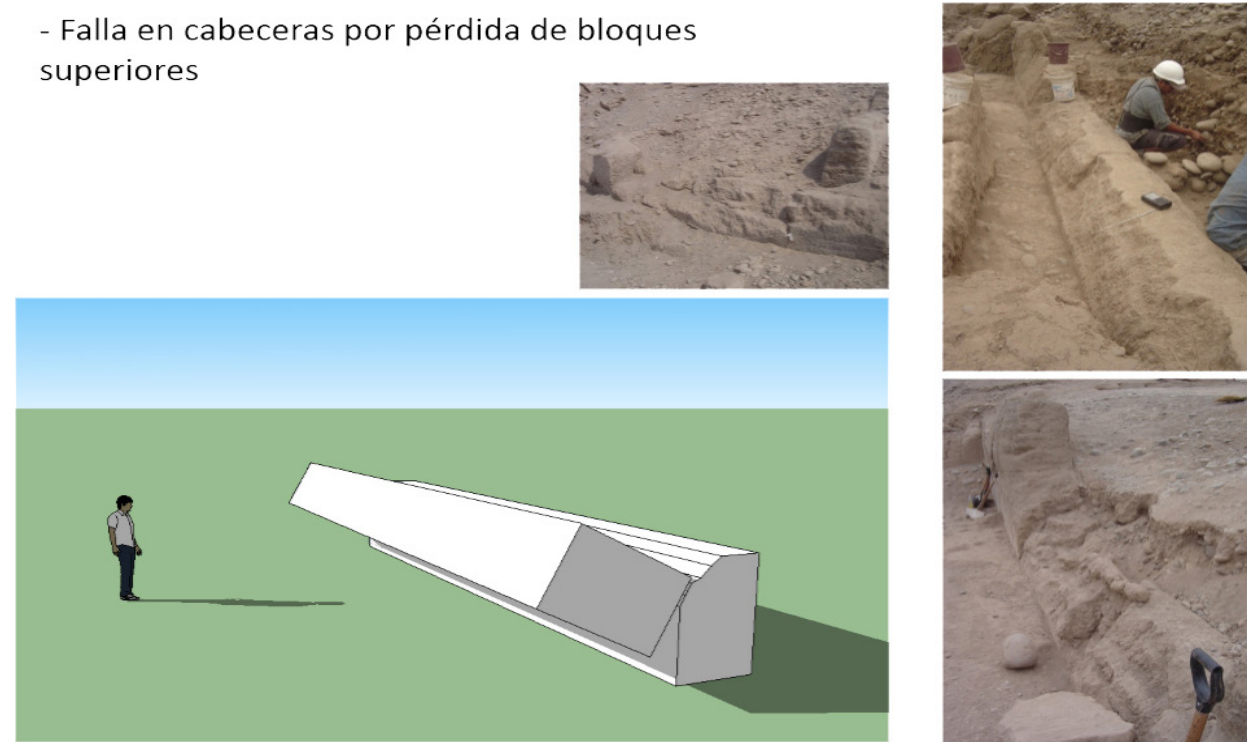

- Deslizamiento de rellenos

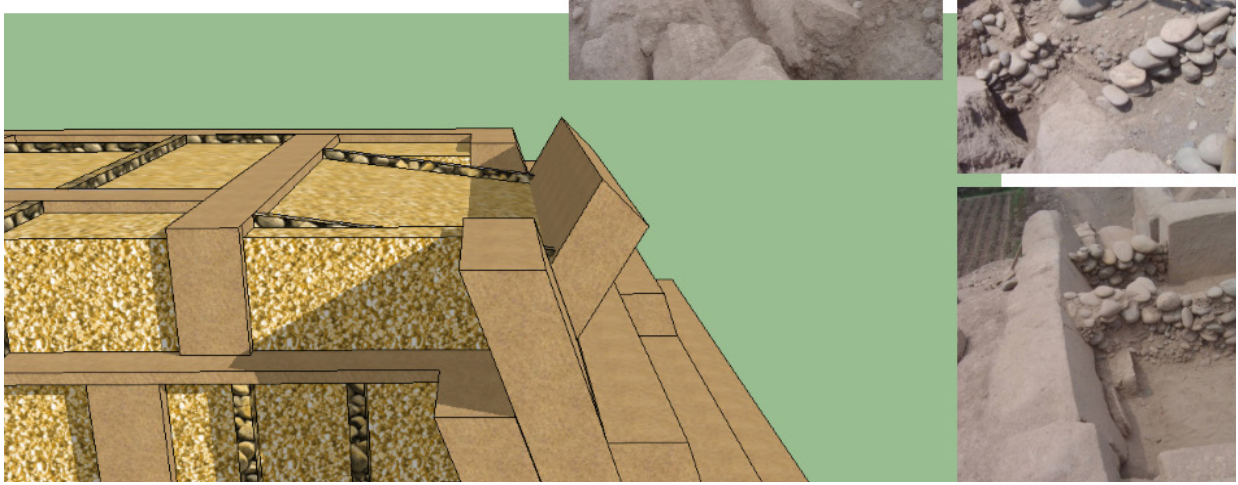

- Colapso parcial
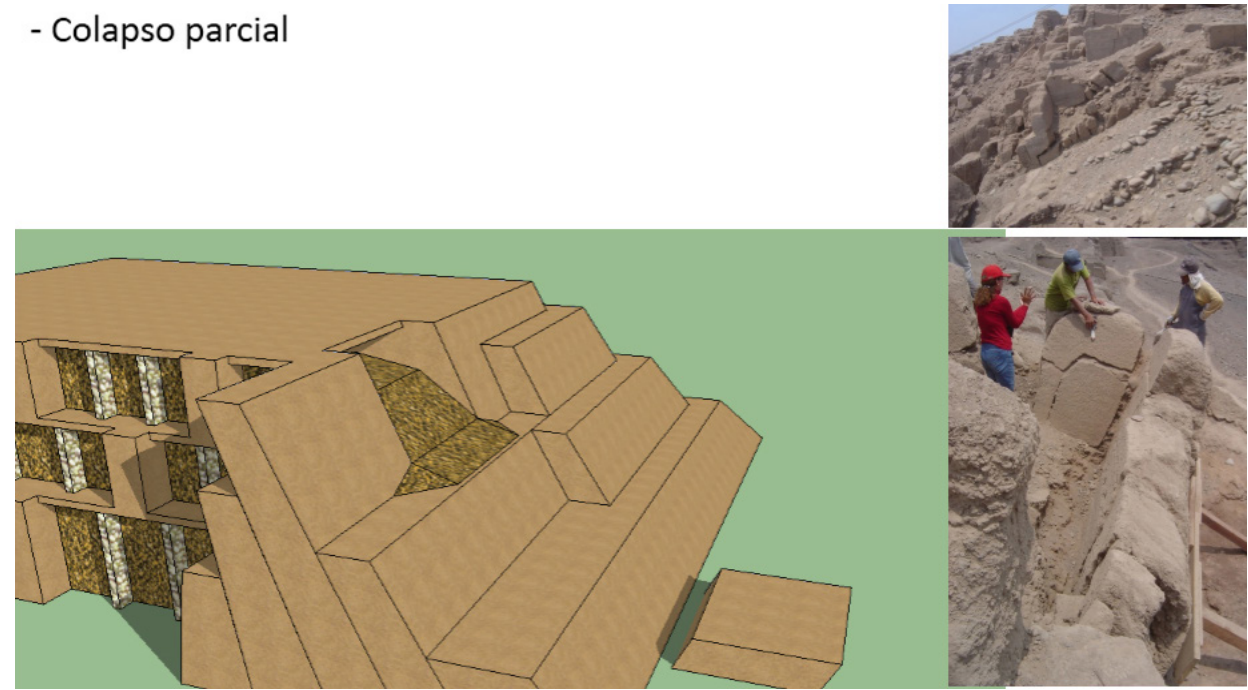


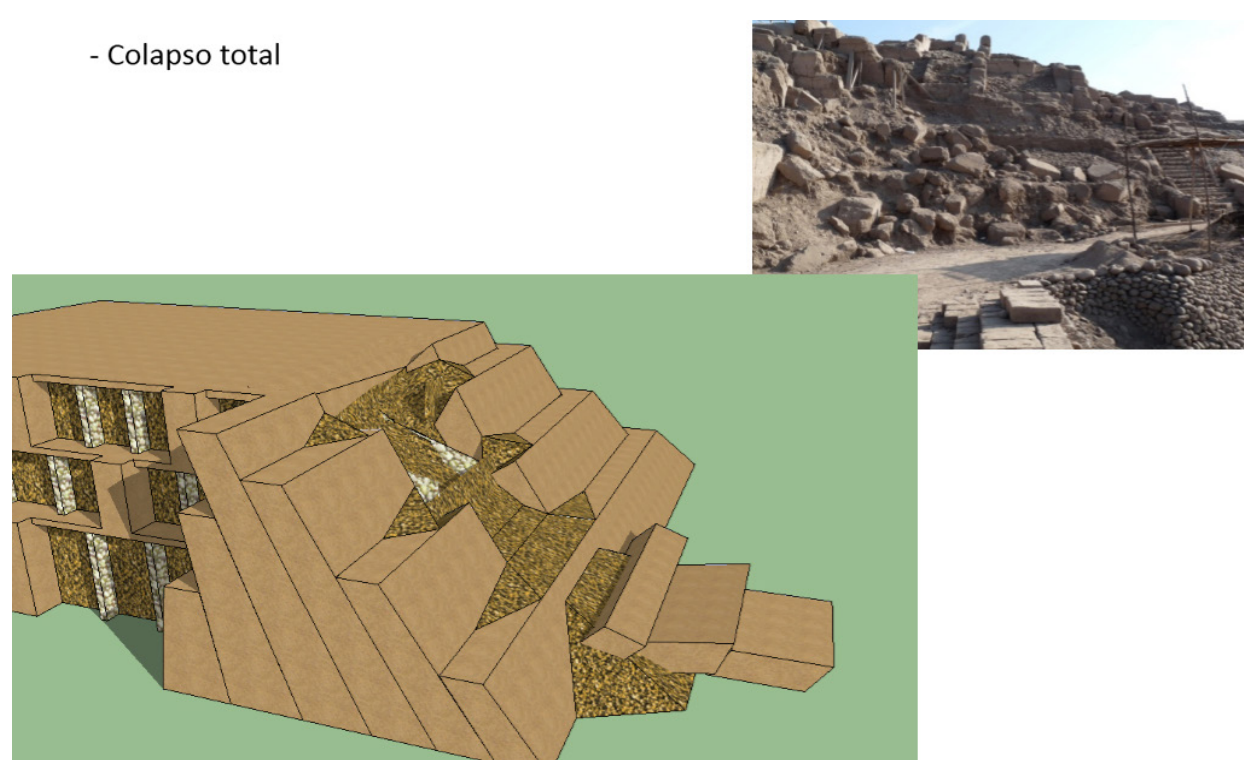

- Asentamiento de pisos o plataformas
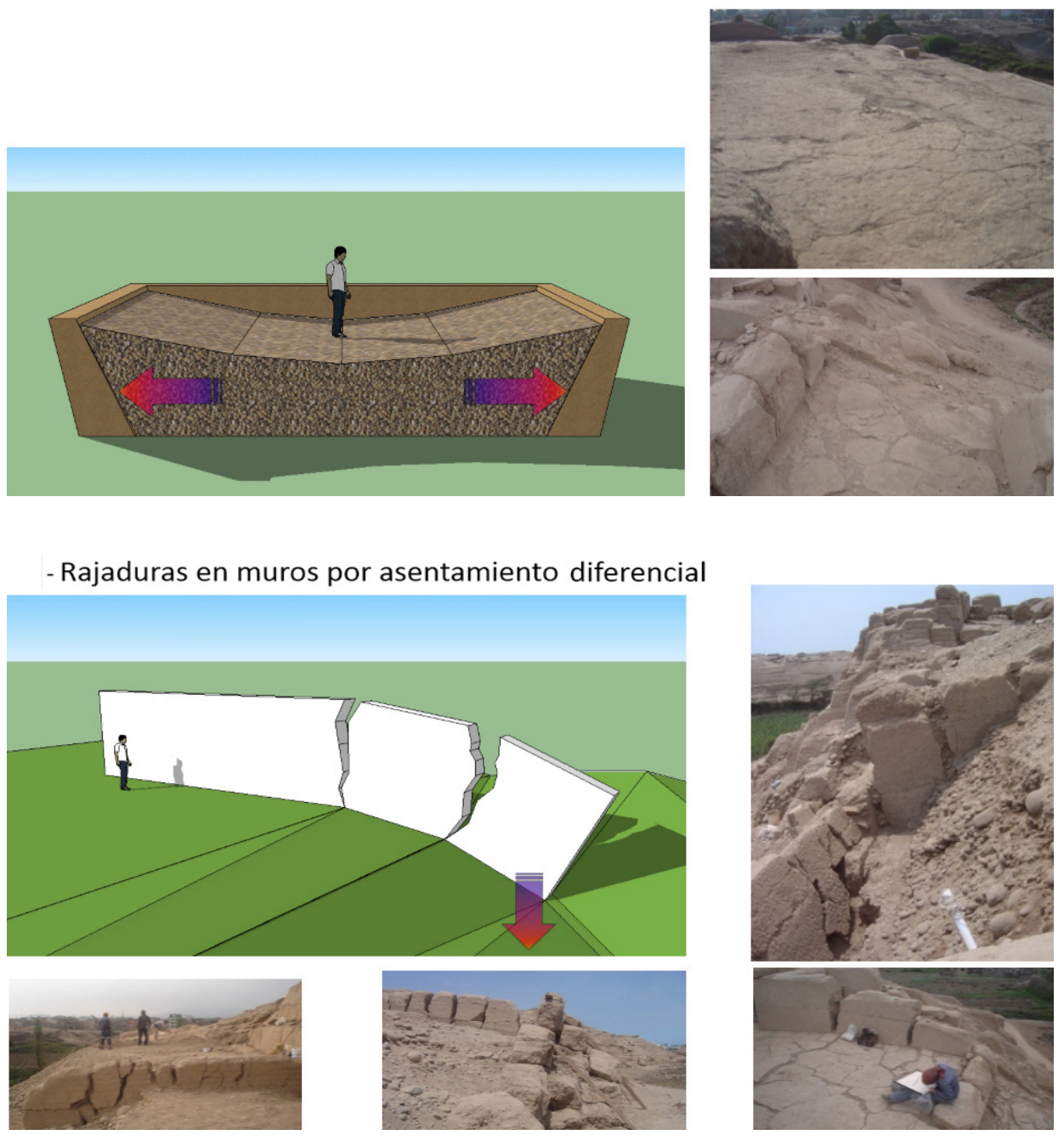

Gráficos 17. Asentamiento de pisos o plataformas.

Fuente. Elaboración propia, Mirna Soto, 2015.

Gráfico 16. Rodamiento de bloques de contención, desplazamiento de estructuras internas, pisos y rellenos. Fuente. Elaboración propia, Mirna Soto, 2015.

\section{- Rajaduras en muros por asentamiento diferencial}

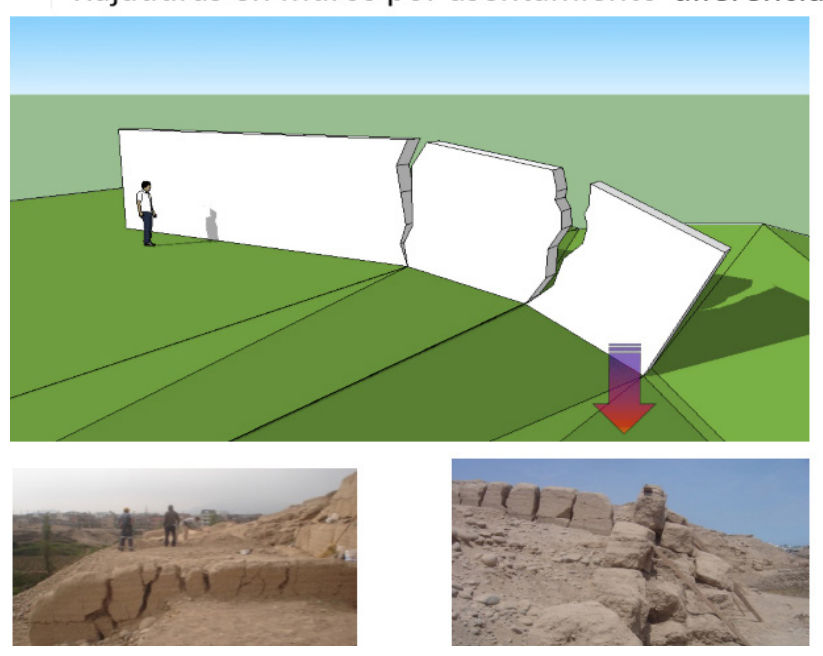

Gráfico 18. Rajaduras en muros por asentamiento diferencial.

Fuente. Elaboración propia, Mirna Soto, 2015. 


\section{Rajaduras en muros por asentamiento diferencial}

Los rellenos sueltos no se compactan uniformemente $y$, por lo tanto, los muros que se apoyan en ellos sufren asentamientos diferenciales que ocasionan típicas fisuras inclinadas (Gráfico 18).

\section{Acciones de Conservación}

Dado el gran valor cultural, histórico y tecnológico que posee el Complejo Mateo Salado, ha sido desde el año 2007 objeto de trabajos de investigación arqueológica y conservación arquitectónica por parte del entonces Instituto Nacional de Cultura.

Los trabajos de conservación realizados en la Pirámide A de Mateo Salado han tenido como principal objetivo garantizar su preservación en el tiempo, y evidenciar sus cualidades artísticas e históricas ante la sociedad actual. El principio fundamental que rige esta tarea de conservación es la preservación de su autenticidad en cuanto a sus cualidades estéticas e históricas, y la contribución a la consolidación de sus estructuras.

\section{Criterios Generales de Intervención en la Conservación de la Pirámide A de Ma- teo Salado}

A partir del estudio detallado del complejo edificado y de la adscripción de la doctrina conservacionista vigente se establecieron ciertos criterios generales de intervención:

- Emplear técnicas y materiales tradicionales a fin de garantizar un mejor comportamiento y eficiencia estructural, así como el respeto a su autenticidad. El adobe como elemento de consolidación de tapiales, BTM y rellenos asegura un menor encogimiento, y facilita el proceso.

- Dadas las características constructivas y la naturaleza de su deterioro, la tarea principal ha sido garantizar la estabilidad de rellenos y bloques de BTM, a través de procesos de consolidación y de reintegración mínima de elementos de contención.

- Como criterio de autenticidad, se ha optado por la diferenciación de partes nuevas y antiguas, que consiste en darle un ligero hundimiento, de aproximadamente $20 \mathrm{~mm}$, a la superficie reintegrada con respecto a la original. Asimismo, se ha colocado una inscripción con el año de fabricación en cada adobe reintegrado (2007-2008).

\section{Acciones Específicas}

Las principales acciones específicas emprendidas fueron las siguientes:

\section{Consolidación de muros}

Para tal efecto se analizó la conveniencia de emplear unidades de mampostería de adobe en vez de tapial, por las siguientes razones:

- Necesidad de disminuir la contracción de secado y generación de fisuras

- Imposibilidad de compactar adecuadamente el tapial y/o BTM en superficies inferiores, verticales y paramentos

- Dificultad de manejar los encofrados de madera en altura

- El empleo del adobe como material de consolidación es una solución simple, práctica y económica. El adobe, por ser unidad seca, aporta un volumen no agrietado y reduce la humedad de los elementos originales contiguos.

- El tapial, los BTM y el adobe son de tierra y, por lo tanto, perfectamente compatibles 
- El adobe permite la diferenciación clara y permanente entre las piezas nuevas y las originales en los sectores reintegrados.

La intervención ha procurado restituir el comportamiento unitario de las cáscaras de cebolla mediante la aplicación de inyecciones de grout de barro líquido tamizado. Dos o tres estructuras simplemente adosadas duplican o triplican su resistencia; sin embargo, dos o tres estructuras unidas que conforman un solo bloque unitario elevan su resistencia exponencialmente. De allí la conveniencia de "pegar" los bloques de tapial (Gráfico 19).

- La reparación de fisuras, rajaduras y grietas permite devolver el comportamiento unitario, y ayuda a disipar la energía sísmica; es decir, un nuevo sismo tendría que separarlos nuevamente y en el intento disiparía parte de su energía (Figura 9).

- Para la reintegración de áreas con erosión basal, a fin de garantizar la estabilidad de los muros de BTM, se ha empleado adobes asentados con barro (Gráfico 20).

Se devolvió verticalidad a los muros inclinados por empujes que habían sido afectados por sismos, pues dichas deformaciones constituyen un riesgo estructural. Para ello, se les "empujó" con ayuda de gatas y se consolidó sus bases (Gráfico 21).

- Como consecuencia de los sismos, recurrentes en nuestro medio, los contrafuertes inferiores hechos de bloques rellenos reducen la esbeltez de los muros superiores, lo cual incrementa el riesgo de colapso en cadena. Durante la intervención fue necesario restaurar la función estructural de dichos bloques a fin de confinar nuevamente el relleno, para lo que se restituyó el material exterior que lo contenía, en este caso con adobes de mediana dimensión (Figura 10).

- Los bloques de consistencia maciza que se encontraban colapsados y fracturados in situ fueron restituidos en su disposición original con la finalidad de que puedan seguir desplegando su potencial artístico e histórico en los lugares donde es imprescindible su presencia por fines estructurales. En tales casos se ha procedido a realizar cuidadosas anastilosis. Sin embargo, debido a la disminución de su capacidad estructural, se ha colocado elementos de refuerzo interior a lo largo de toda su longitud un muro de adobe asentado con barro (de $0.40 \mathrm{~m}$ de espesor mínimo), que tiene la función de absorber los empujes del relleno (Gráfico 22).

\section{Estabilización y consolidación de rellenos expuestos}

Esta tarea se realizó mediante la restitución de las unidades de piedra caídas o deslizadas. Se les devolvió el ligero talud original, que contribuye a la estabilidad, y se restituyó por completo el mortero de barro entre piedras, que restablece la adherencia entre ellas.

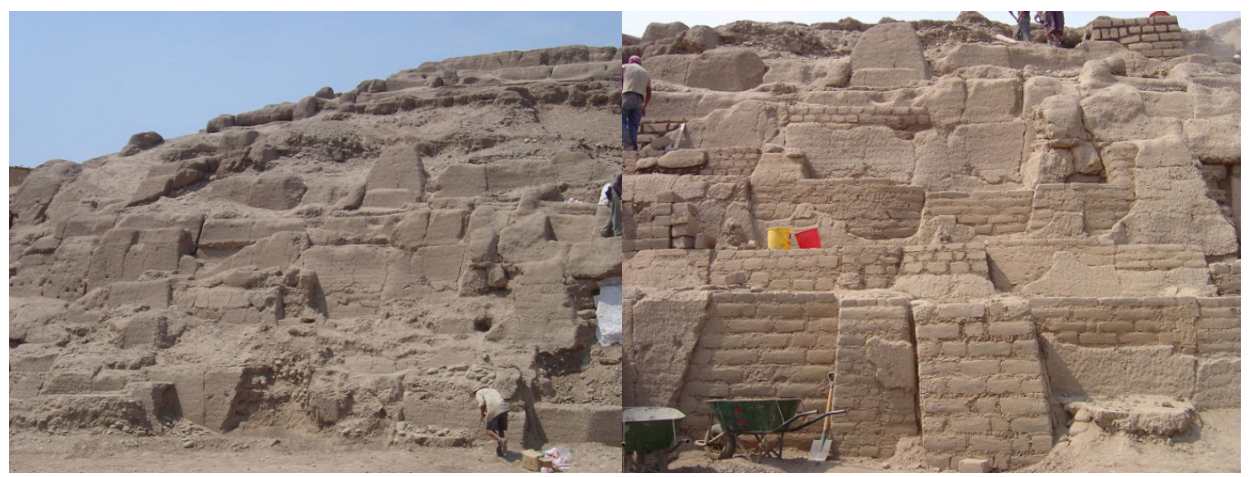

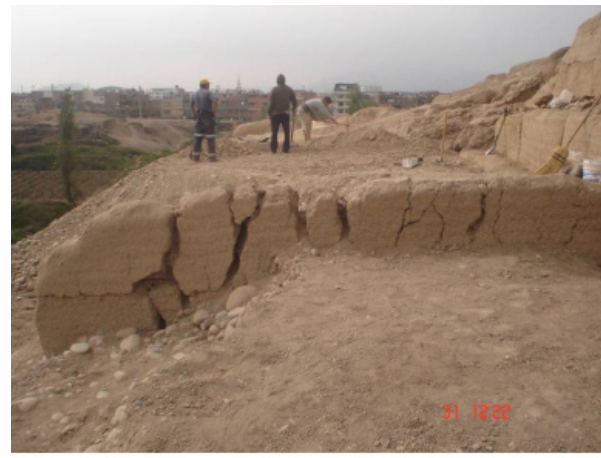
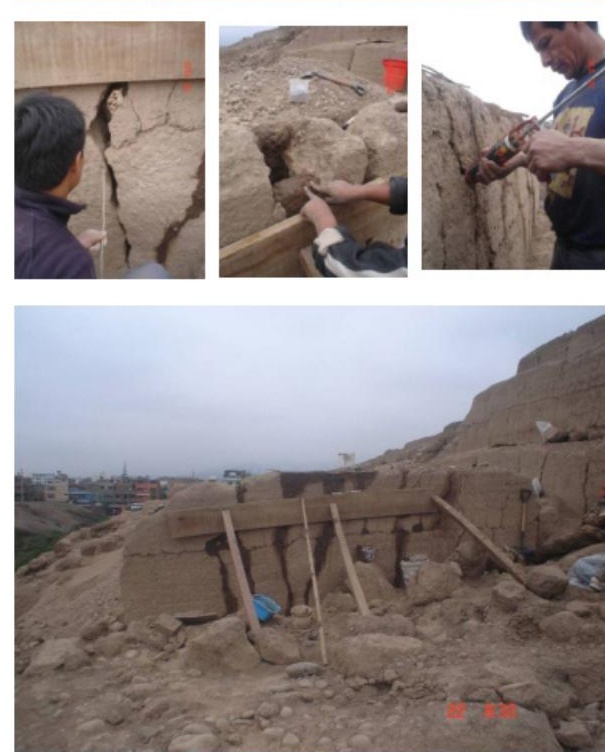

Figura 9. Inyección de bloques con grout.

Fuente. Archivo fotográfico Mirna Soto, 2015.

Figura 10. Fachada Sur, Pirámide A. Antes y después de la intervención. Fuente. Archivo fotográfico Mirna Soto, 2015. 
devenir Vol. 2, N³, ENERO- JUNIO 2015, Pp. 22-44 - EstudIOS I ISSN 2312-7570

UnIVERSIDAD NACIONAL DE INGENIERÍA, LIMA

Gráfico 19. Restitución de comportamiento unitario. Reconexión de bloques con mortero y/o inyecciones.

Fuente. Elaboración propia, Mirna Soto, 2015 .

Gráfico 20. Reintegración de área con erosión basal, empleo de adobes.

Fuente. Elaboración propia, Mirna Soto, 2015.
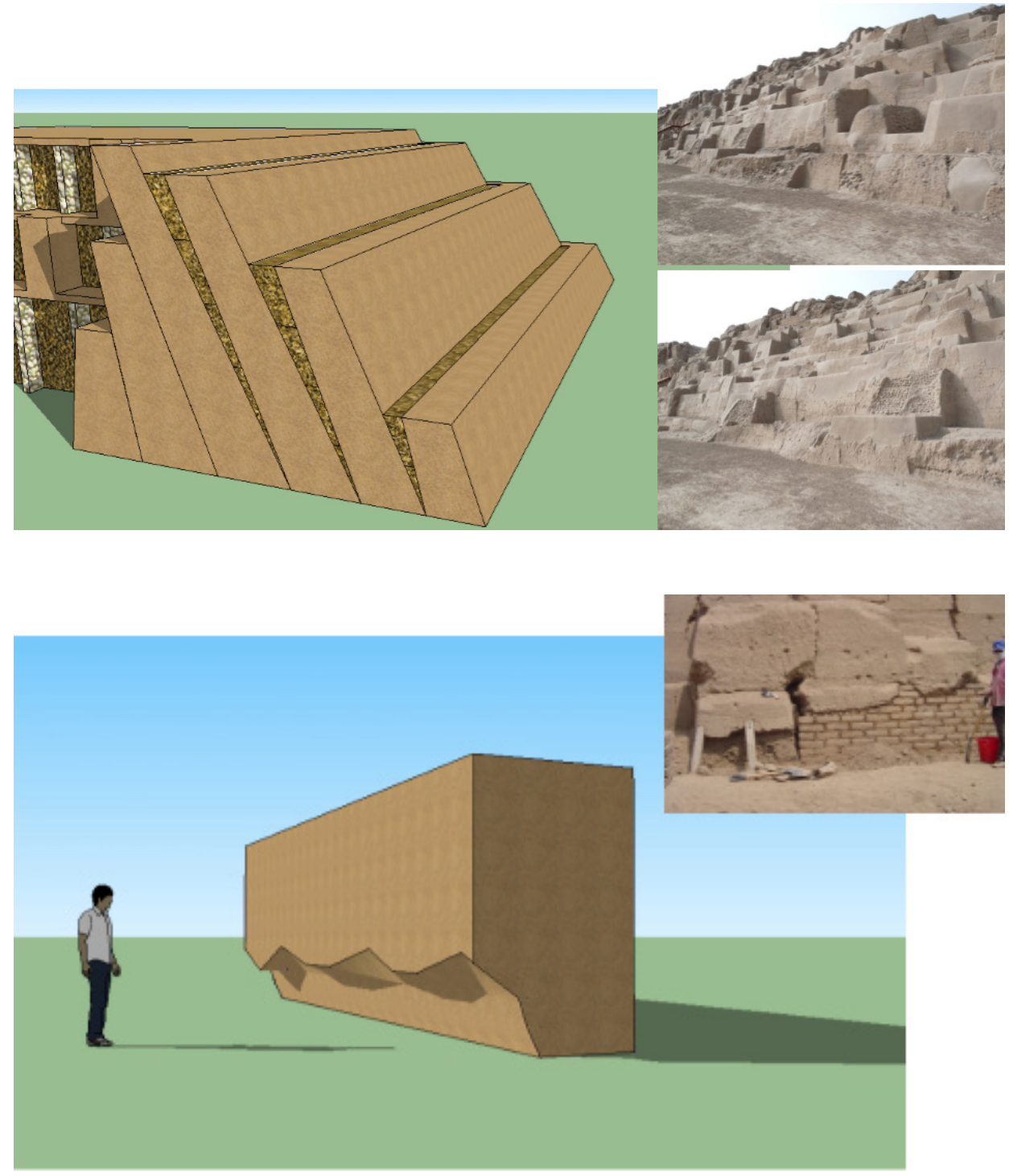

Reintegración de área con Erosión Basal. Reintegración con adobes.

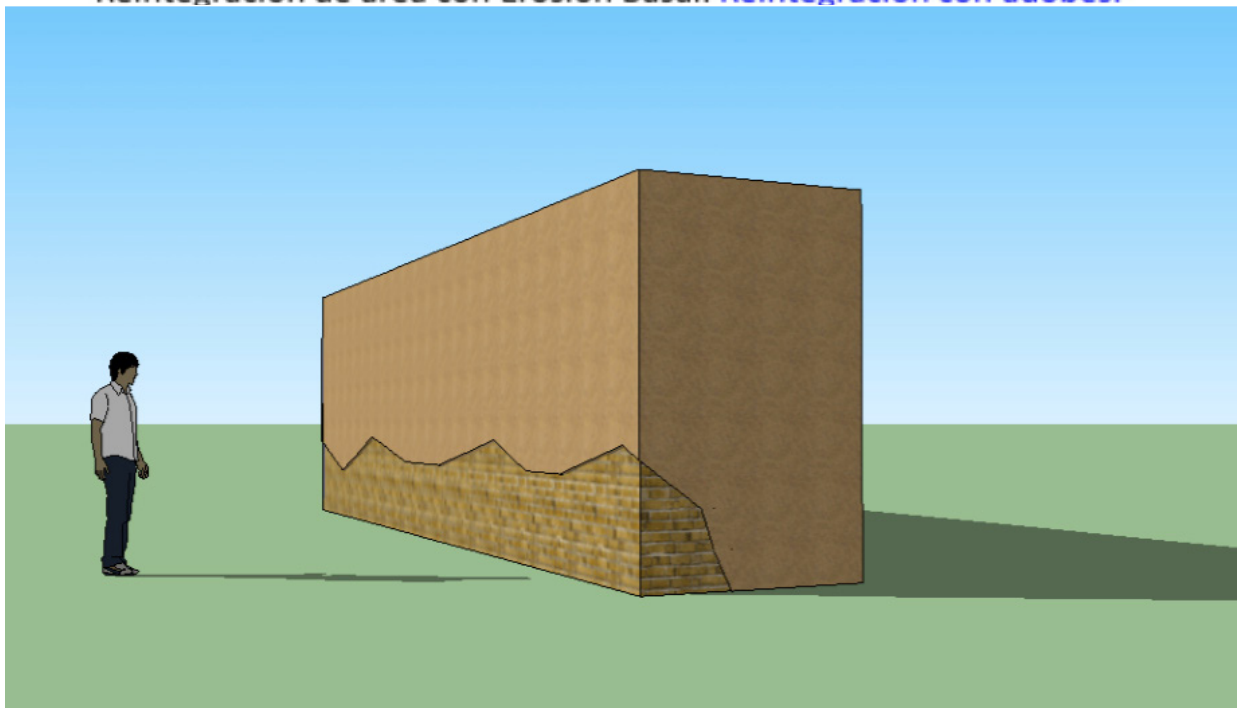




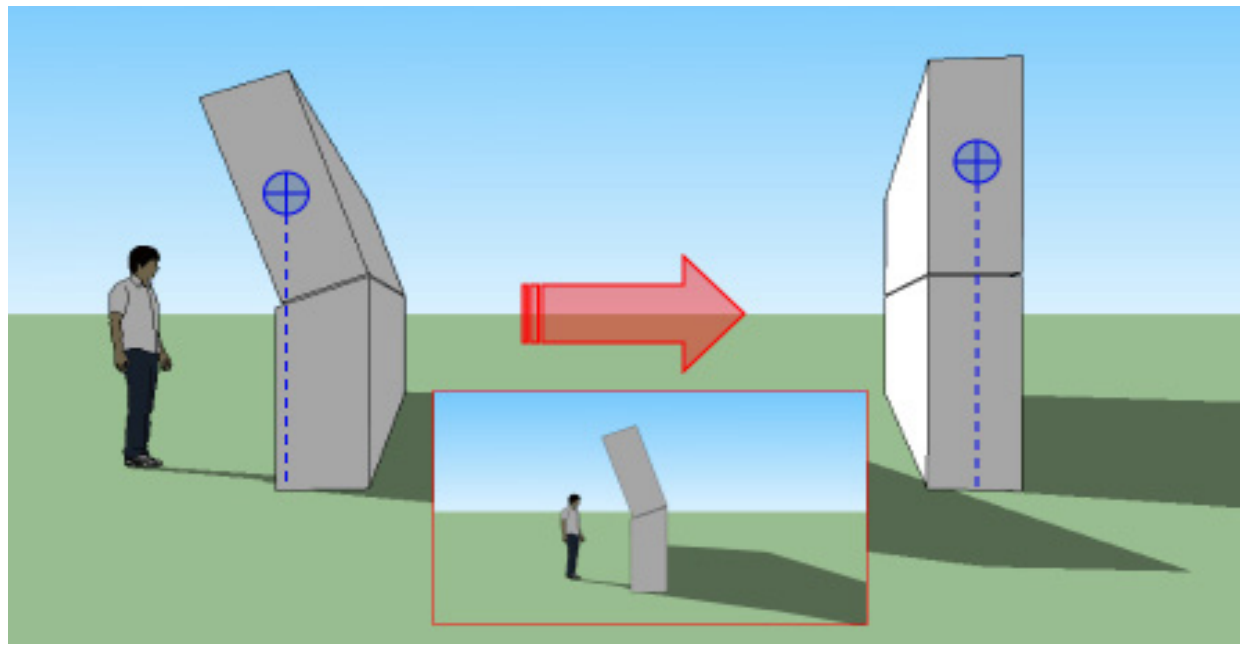

\section{Tapado y entierro de zonas con alto riesgo}

En los casos de mayor riesgo estructural, donde se presentaban colapsos y la evidencia arqueológica se encontraba muy disturbada, se optó por el entierro de la estructura tras estabilizar previamente su situación estructural. Para la estabilización se empleó gran cantidad de adobes que fueron colocados de forma escalonada, a manera de puntal, desde la base de la pirámide hasta el punto más alto, para contrarrestar así el desplazamiento de las estructuras (Gráfico 23).

\section{Apuntalamiento externo}

En casos de riesgo estructural donde se presentaban estructuras esbeltas en peligro de colapso se optó por incorporar elementos de apuntalamiento: puntales de madera o tipo contrafuerte hechos de adobe que permitan la clara diferenciación formal y evidencien su contemporaneidad (Gráfico 24).

\section{Conclusiones}

El Perú posee un vasto patrimonio monumental arqueológico, del cual las huacas o edificaciones prehispánicas ubicadas en la costa peruana son parte importante. Las edificaciones yschma construidas entre el siglo XI y XV, como el Complejo Maranga, el Complejo Mateo Salado, Huantinamarca, Huantille, San Borja, La Merced y muchas otras, tienen a la tierra como el principal material de construcción, material frágil, vulnerable a los movimientos sísmicos que son tan frecuentes en Lima. Esta característica fundamenta la necesidad, de parte de todo profesional involucrado en la conservación, de comprender la naturaleza del material y el comportamiento físico-estructural de sus componentes.

La tierra en el mundo andino tiene carácter sagrado: su empleo como material de construcción le confiere un carácter sacro a la edificación.

La técnica constructiva empleada por los Yschma en los muros no es precisamente tapial, ya que se trata de tierra colocada en sitio con las manos, sin el empleo de encofrados rígidos, lo cual permite definirla como Bloques de Tierra Modelada o BTM. El relleno interior de la huaca está elaborado a base de emparrillado de muros de canto rodado asentado con escaso mortero de barro, además de tierra suelta y piedras pequeñas que rellena los espacios del emparrillado. La naturaleza poco estable de este sistema dio lugar a que los antiguos constructores reforzasen los muros mediante adosamientos de bloques, lo cual aumenta el índice de masa o esbeltez.
Gráfico 21. Restitución de verticalidad. Alineación vertical del centro de masas.

Fuente. Elaboración propia, Mirna Soto, 2015. 
devenir Vol. 2, N³, ENERO- JUNIO 2015, PP. 22-44 - EstudIOS I ISSN 2312-7570

UNIVERSIDAD NACIONAL DE INGENIERÍA, LIMA

Gráfico 22. Aporte de resistencia al muro histórico, con muro de refuerzo interior.

Fuente. Elaboración propia, Mirna Soto, 2015.

Gráfico 23. Consolidación y reentierro.

Fuente. Elaboración propia, Mirna Soto, 2015.

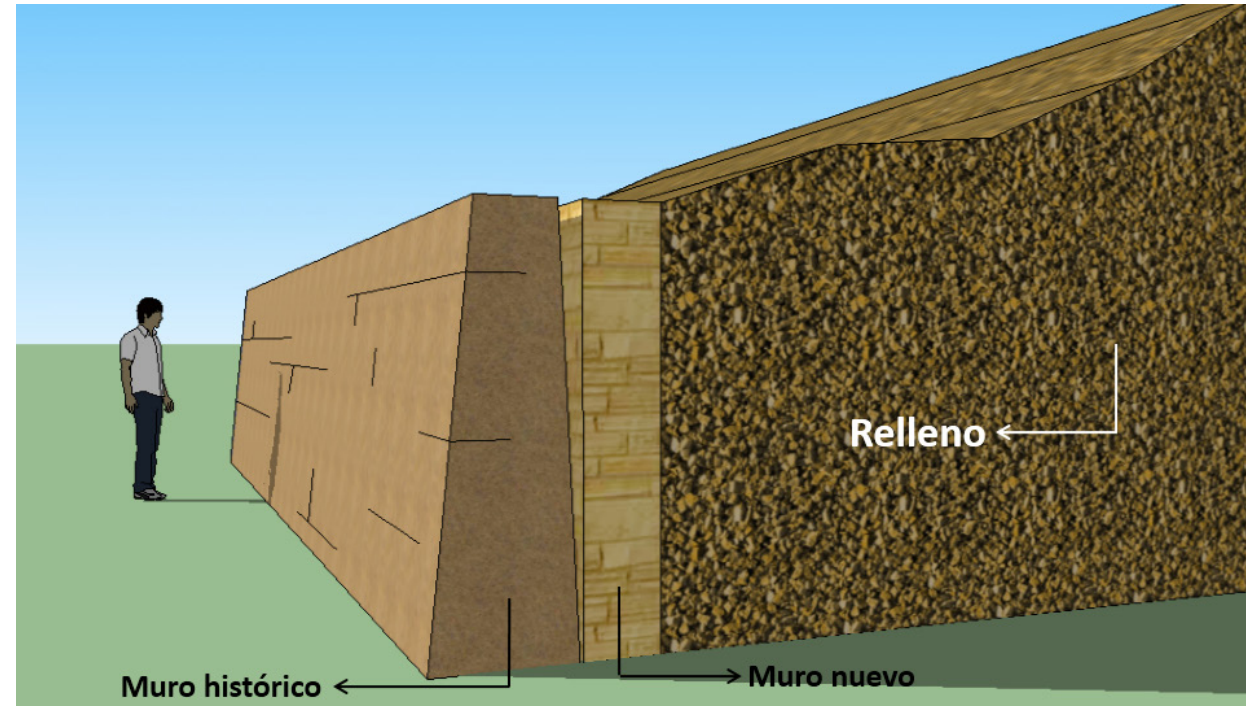

- Consolidación y tapado
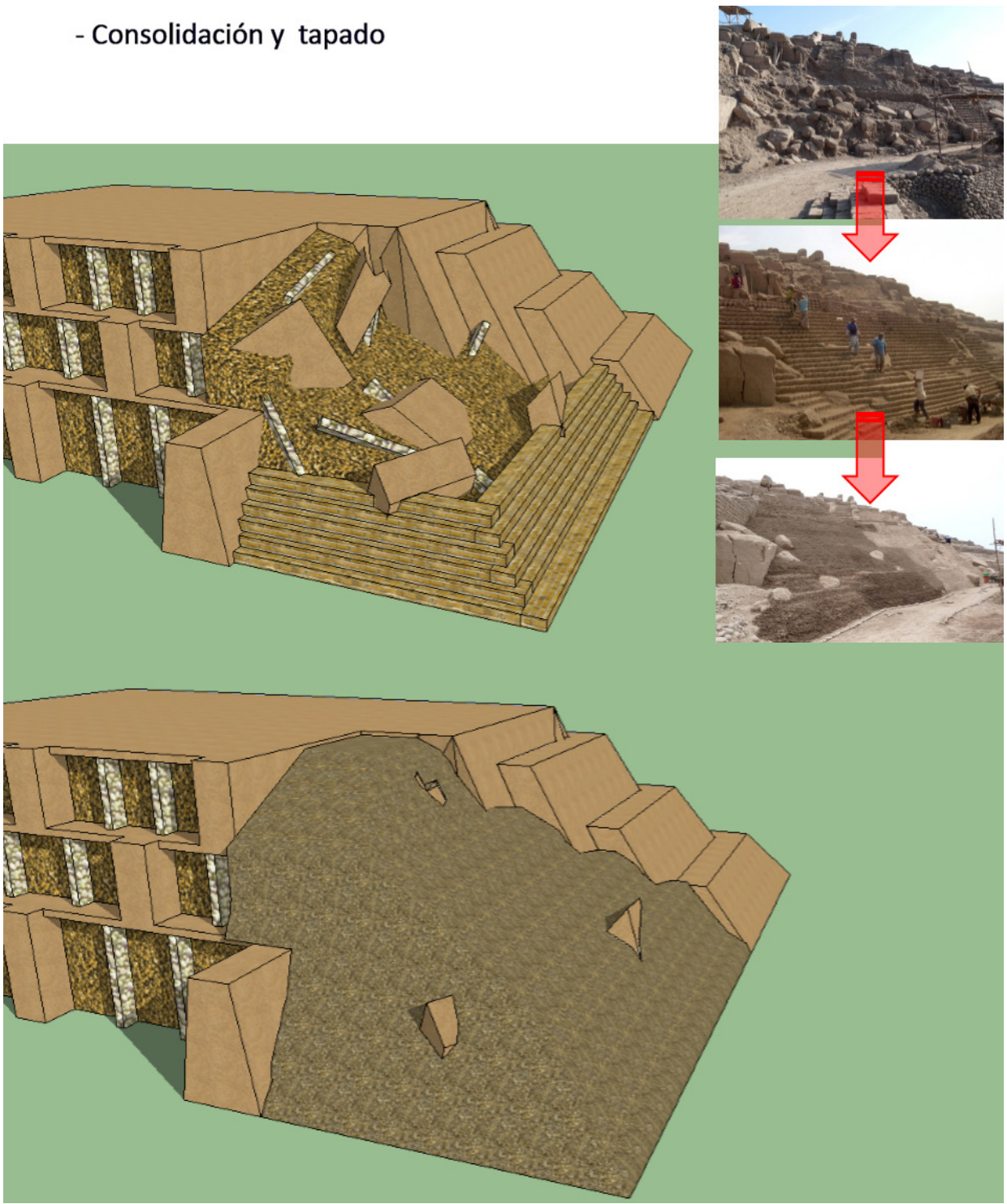


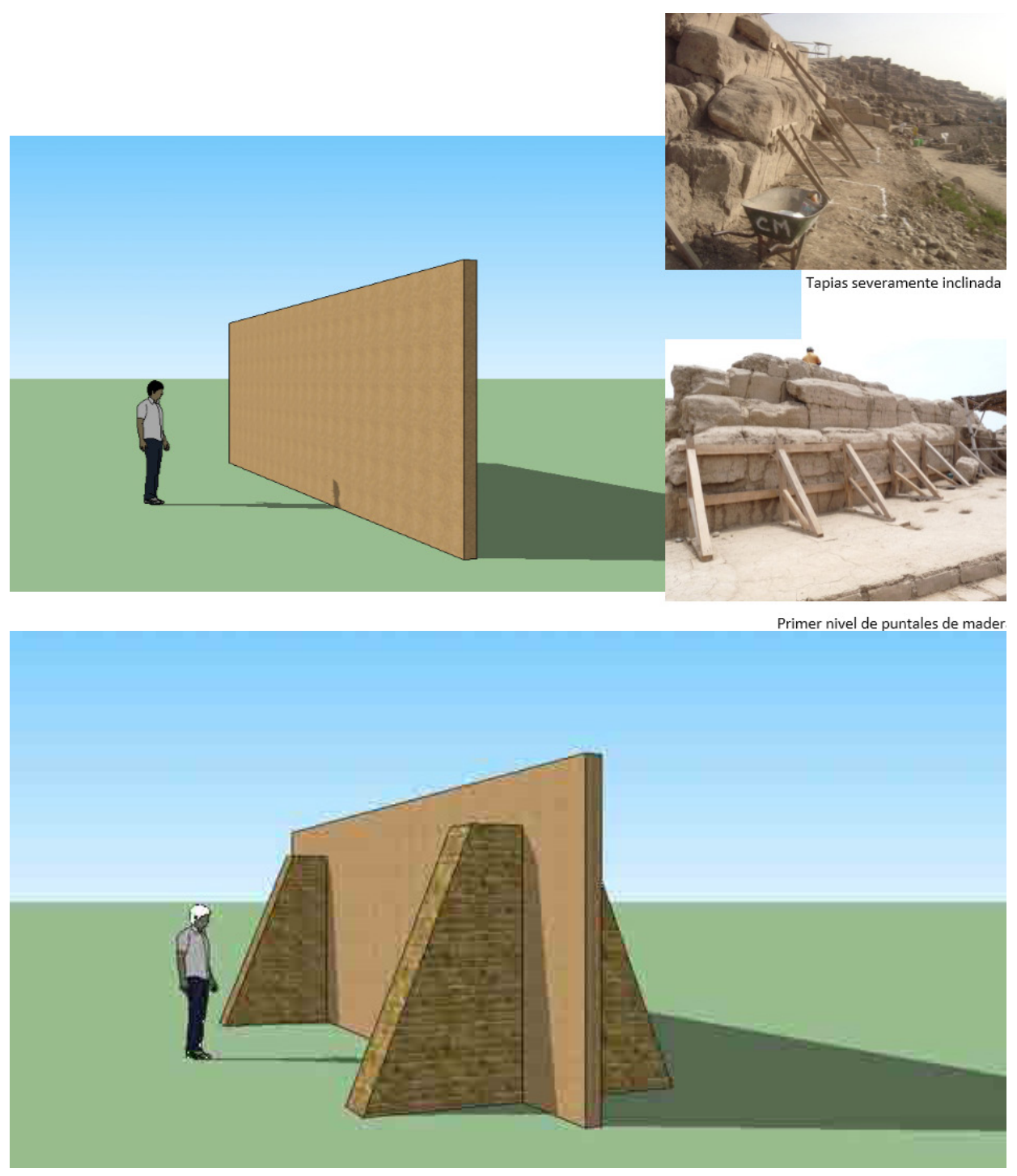

Las principales formas de deterioros observables en las estructuras que componen el complejo son la erosión, la inestabilidad de muros, el colapso parcial y total de muros de contención, y el deslizamiento de rellenos y asentamientos como consecuencia de movimientos sísmicos, empuje de rellenos y factores humanos.

El tratamiento general de la conservación de la pirámide A de Mateo Salado se ajusta a los conceptos internacionales comúnmente aceptados: mínima intervención, compatibilidad de materiales, respeto a la autenticidad, diferenciación de intervenciones recientes, etc. La intervención se centró en la consolidación estructural, basada en la estabilización de rellenos y la restitución del funcionamiento estructural de los bloques de tierra modelada.

Cabe resaltar que esta amigable y totalmente respetuosa consolidación podría no ser suficiente para que el complejo resista terremotos de mediana o gran intensidad en el futuro, ya que existen factores internos que se extienden hasta el núcleo mismo de la edificación. Por ello es necesario seguir desarrollando criterios de desempeño de comportamiento sismorresistente en edificaciones arqueológicas de tierra, respetando siempre el valor cultural.
Gráfico 24. Para el apuntalamiento externo se empleó contrafuertes de adobe o puntales de madera a fin de asegurar la estabilidad de muros esbeltos o con inminente riesgo de colapso.

Fuente. Elaboración propia, Mirna Soto, 2015. 
devenir Vol. 2, N³, ENERO- JUNIO 2015, PP. 22-44 - ESTUDIOS I ISSN 2312-7570

UNIVERSIDAD NACIONAL DE INGENIERÍ, LIMA

La experiencia de recuperación del Complejo Mateo Salado es pionera por su carácter interdisciplinario; trabajar con un equipo conformado por arqueólogos, arquitectos e ingenieros civiles ha permitido una mejor aproximación a la problemática cuyo abordaje desde distintas perspectivas permitió enriquecer las soluciones de estabilización.

\section{Referencias}

Barrow, J., Porter, D., Farneth, S. y Tolles, L. (2005). Las Flores Adobe Seismic Retrofit: A Case Study Using GSAP Guidelines and Development of Compatible and Reversible Grouts. International Conference SismoAdobe 2005. Conferencia llevada a cabo en Pontificia Universidad Católica del Perú, Lima, Perú.

Brandi, C. (1988). Teoría de la restauración. Madrid, España: Editorial Alianza Forma.

Blondet, M., Vargas, J. y Tarque, N. (2007). Behavior of earthen structures during the Pisco earthquake, Peru. Lima, Perú: Pontificia Universidad Católica del Perú.

Blondet, M., Vargas, J., Ginocchio, F., Morales, K. y Iwaki, C. (2007). Estudio Preliminar del Uso de Grouts de Barro para Reparar Fisuras Estructurales en Muros Históricos de Adobe. AdobeUSA 2007, EE.UU.

Blondet, M., Vargas, J., Ginocchio, F., Villa Garcia, G., Morales, K. y Iwaki, C. (2007). Reparación de grietas en construcciones históricas de tierra en áreas sísmicas. (Informe Final DAI). Lima, Perú: Pontificia Universidad Católica del Perú.

Blondet, M., Vargas, J., Ginocchio, F., Villa García, G., Sánchez, K., Fernández, C. y Chang, J. (2008). Reparación de grietas en construcciones históricas de tierra en áreas sísmicas. Parte ll. (Informe Final DAI). Lima, Perú: Pontificia Universidad Católica del Perú.

Canziani, J. (2009). Ciudad y territorio en los Andes. Contribuciones a la historia del urbanismo prehispánico. Lima, Perú: Pontificia Universidad Católica del Perú.

González-Varas, I. (2006). Conservación de bienes culturales: Teoría, historia, principios y normas. Madrid, España: Cátedra.

Figueroa, A. (2007). Complejo arqueológico Mateo Salado. Proyecto de investigación, conservación y puesta en valor - I Etapa. Lima, Perú: Instituto Nacional de Cultura.

Instituto Nacional de Cultura. (2009). Arqueología de Lima: Mateo Salado. Cuadernos del Patrimonio Cultural 2. Lima. Perú.

Pérez, M. (2000). Investigación en Mateo Salado. Cuaderno de Investigación № 1 del Museo Nacional de Arqueología, Antropología e Historia del Perú. Lima, Perú.

Tello, J. C. (1999). Arqueología del valle de Lima. Cuadernos de Investigación del Archivo Tello 1. Lima, Perú: Museo de Arqueología y Antropología de la Universidad Nacional Mayor de San Marcos.

Tolles, E. L., Kimbro, E. E., Webster, F. A. \& Ginell, W. S. (2000). Seismic Stabilization of Historic Adobe Structures (Final Report of the Getty Seismic Adobe Project). California, EE.UU.: The Getty Conservation Institute. Recuperado de http://www.getty.edu/conservation/publications resources/pdf_publications/pdf/seismicstabilization.pdf

Santa Cruz, E. (2009). Proyecto de intervención en el sector del Acllahuasi del Sitio Arqueológico de Pachacamac (Informe Final). Lima, Perú: Organización de las Naciones Unidas para la Educación, la Ciencia y la Cultura.

Vargas, J., Blondet, M., Ginocchio, F. y Villa-García, G. (1978). La vivienda rural de adobe. Lima, Perú: Pontificia Universidad Católica del Perú.

Vargas, J., Bariola, J., Blondet, M. y Metha, P. (1984). Seismic strength of adobe masonry. Lima, Perú: Pontificia Universidad Católica del Perú.

Vargas, J., Blondet, M., Cancino, C., Ginocchio, F., Iwaki, C. y Morales K. (2008). Experimental results on the use of mud-based grouts to repair seismic cracks on adobe walls. Bath, Inglaterra: CRC Press.

WJE Consultants. (2004). Rancho San Andres Castro Adobe, Rehabilitation Project. California State Parks. California, EE.UU: Autor. 